\title{
One-pot Amide Bond Formation from Aldehydes and Amines via a Photoorganocatalytic Activation of Aldehydes
}

\section{Giorgos N. Papadopoulos and Christoforos G. Kokotos ${ }^{*}$}

Laboratory of Organic Chemistry, Department of Chemistry, National and Kapodestrian University of Athens,

Panepistimiopolis, Athens 15771, Greece

\section{SUPPORTING INFORMATION}




\begin{tabular}{|l|c|}
\hline & Page \\
\hline General Photochemical Setup & S2 \\
\hline NMR Spectra & S3 \\
\hline HPLC Data & S31 \\
\hline
\end{tabular}




\section{General Photochemical Setup}
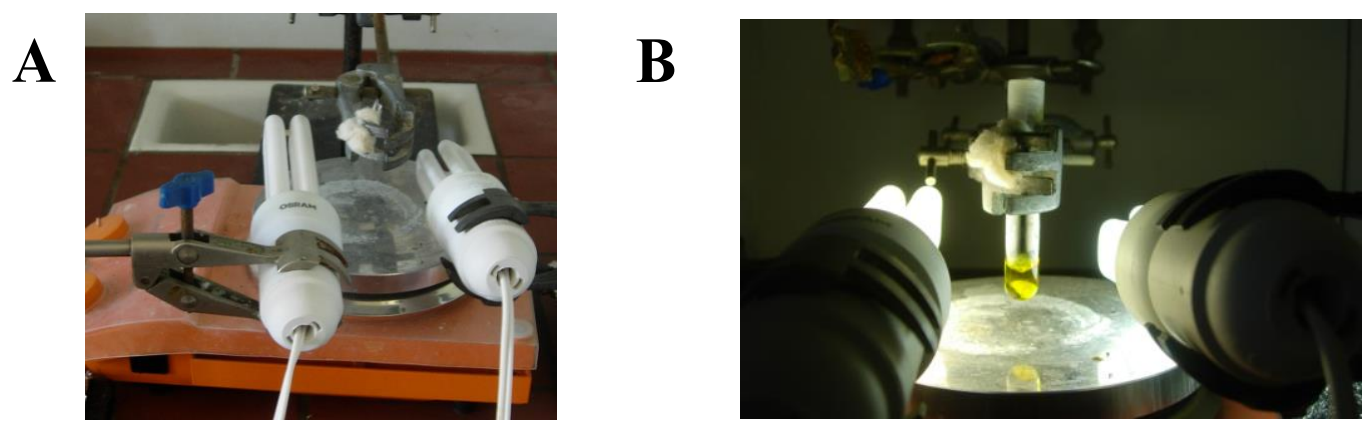

Scheme. A: 2 x $15 \mathrm{~W}$ fluorescent household lamps utilized for the photocatalytic reaction. Bulbs are placed symmetrically $2 \mathrm{~cm}$ away from the reaction tube. B: Beginning of the reaction between heptanal with di-isopropyl azodicarboxylate (bright yellow colour of the di-isopropyl azodicarboxylate observed). For more information on the photocatalytic setup and mechanistic investigations, see: Chem. Eur. J., 2014, 20, 13811. 


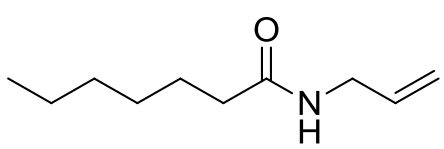

$3 a$
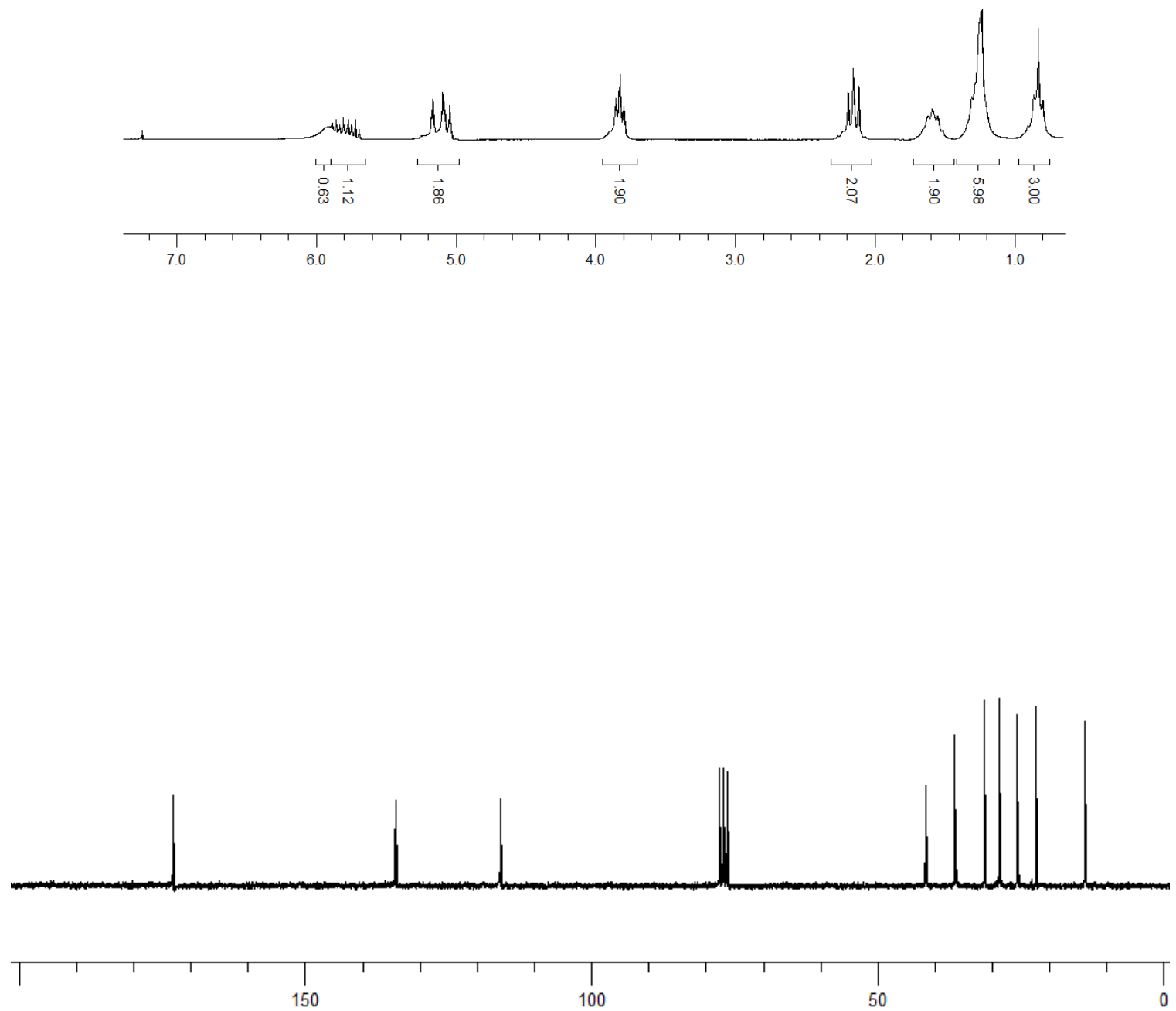


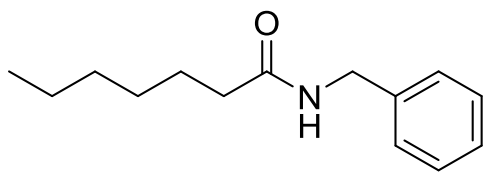

3b
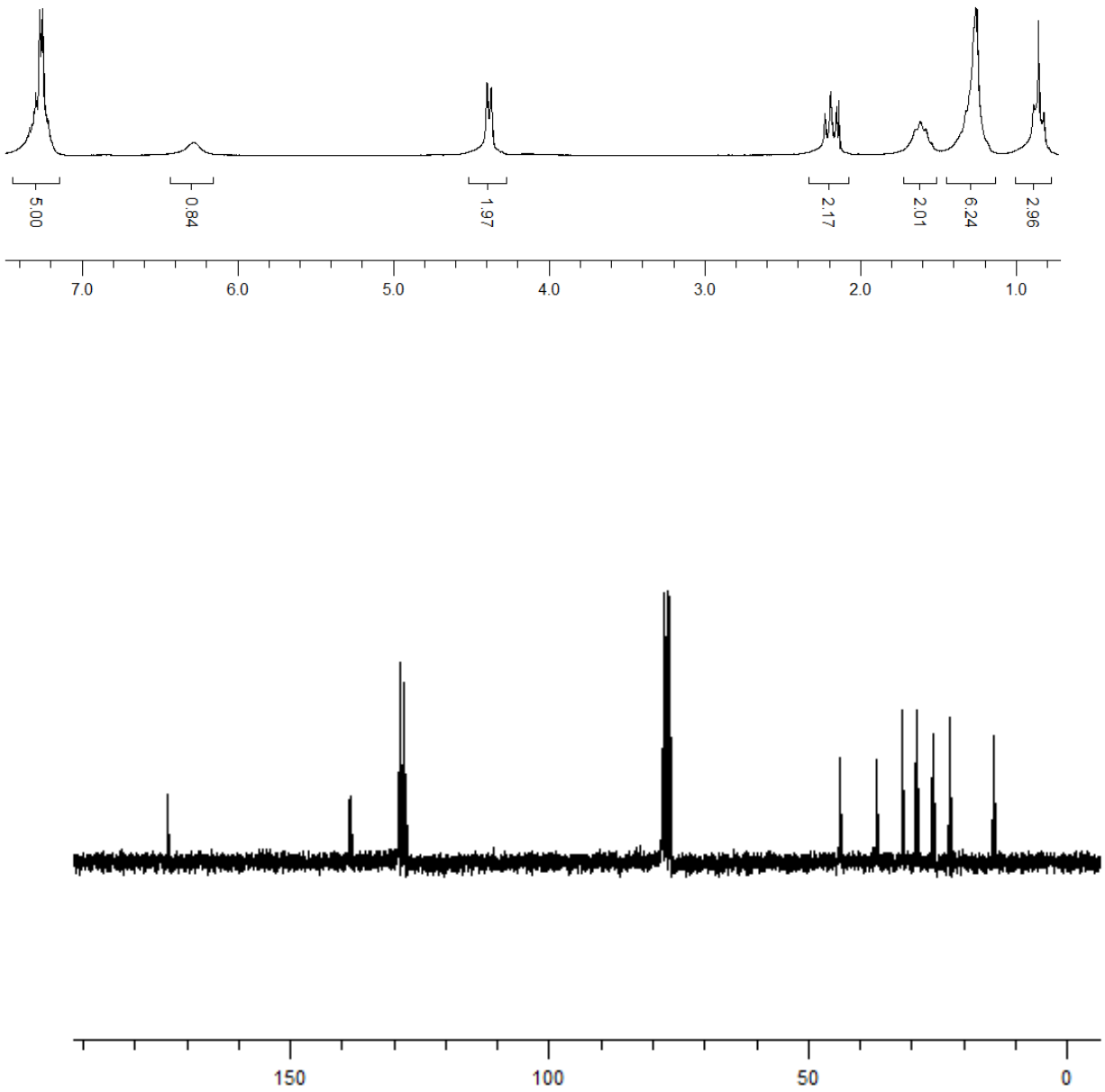


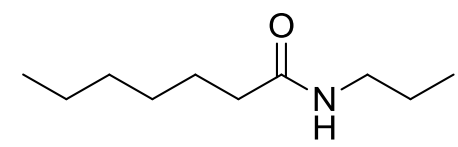

$3 c$
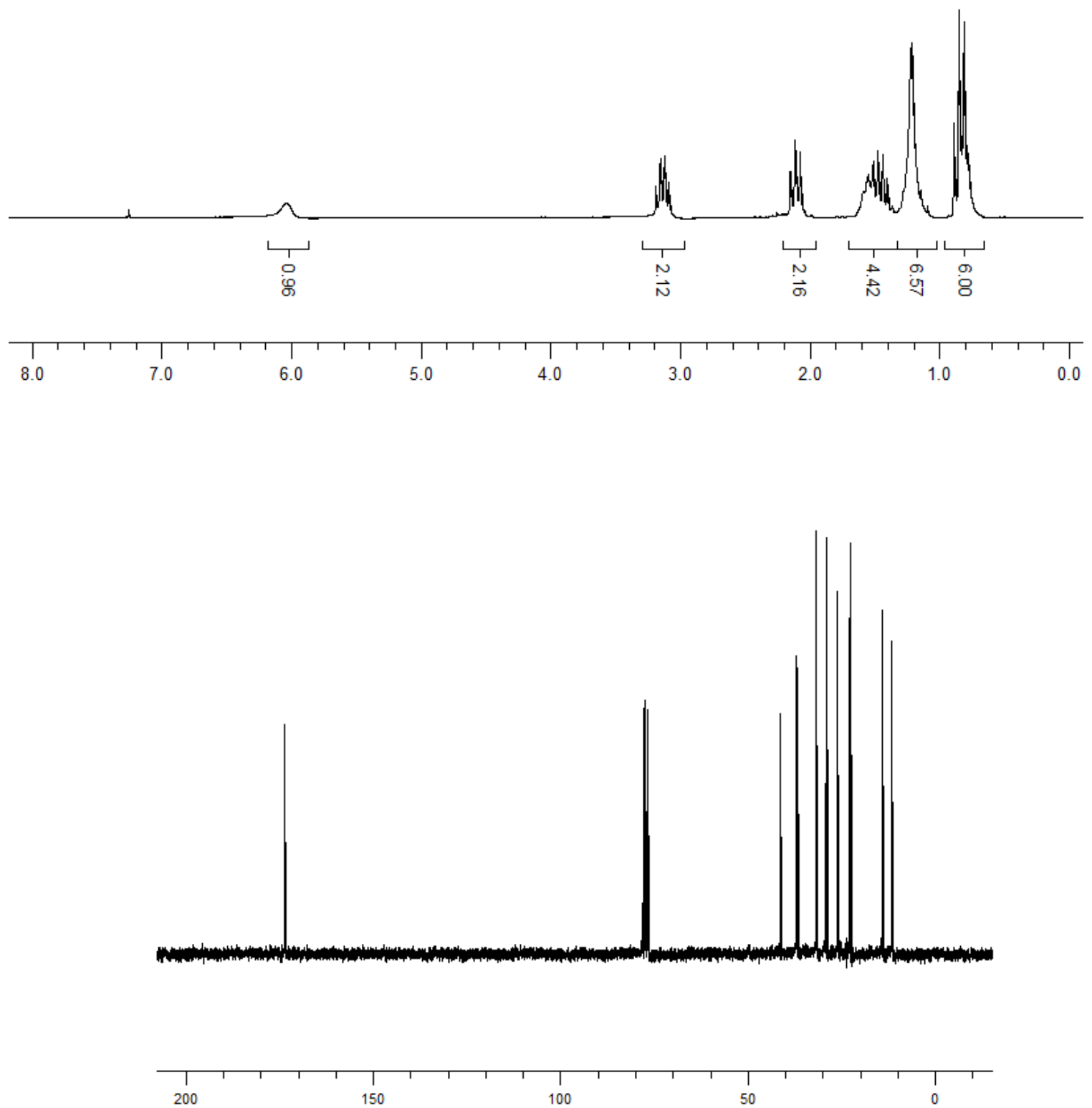

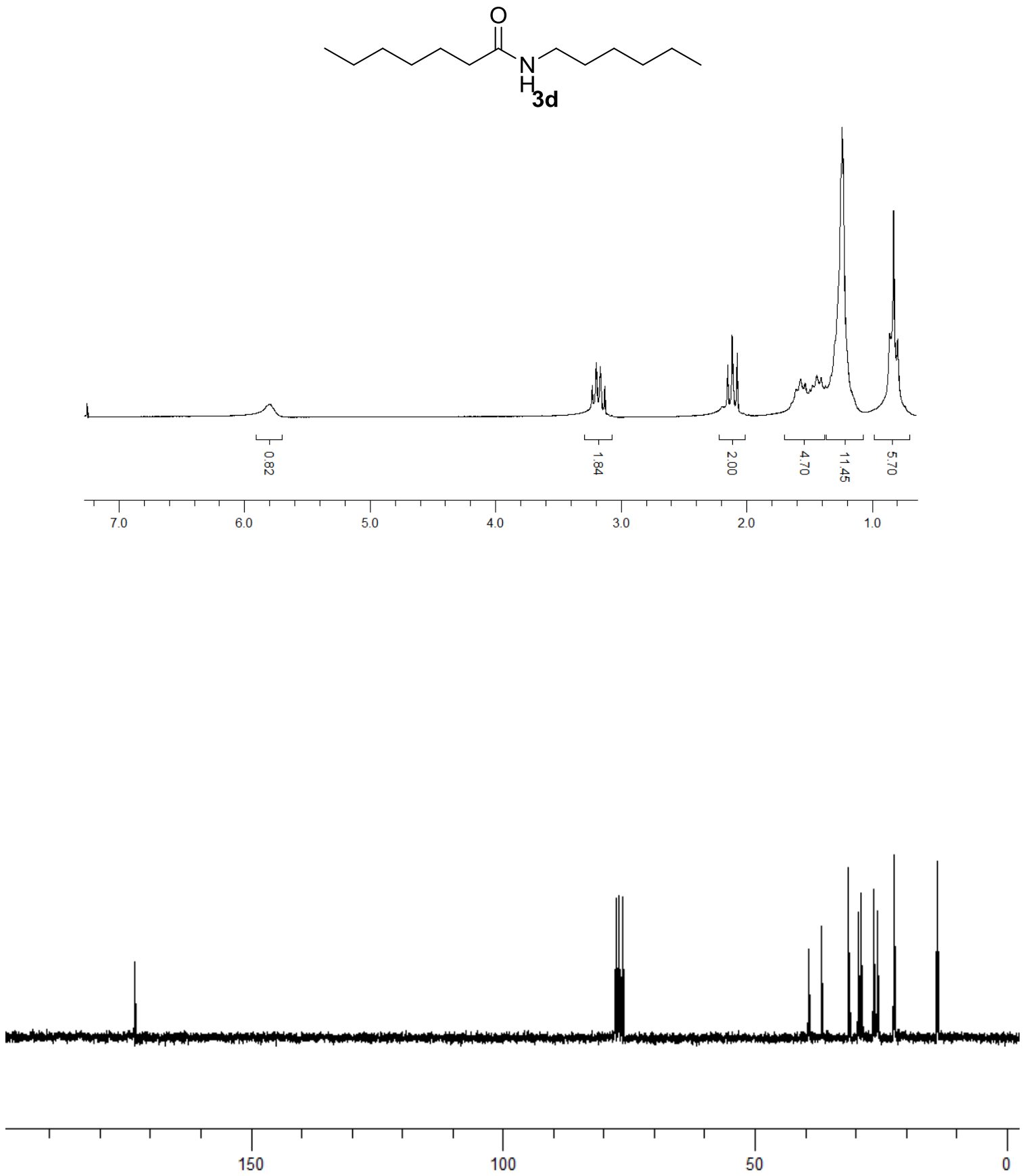


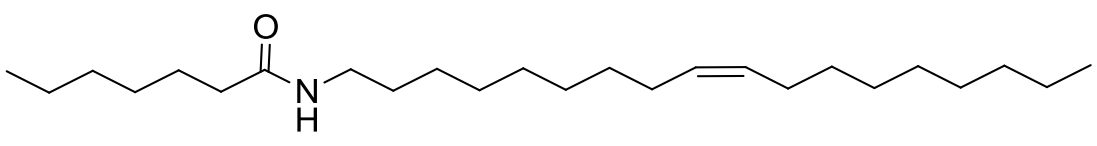

$3 e$
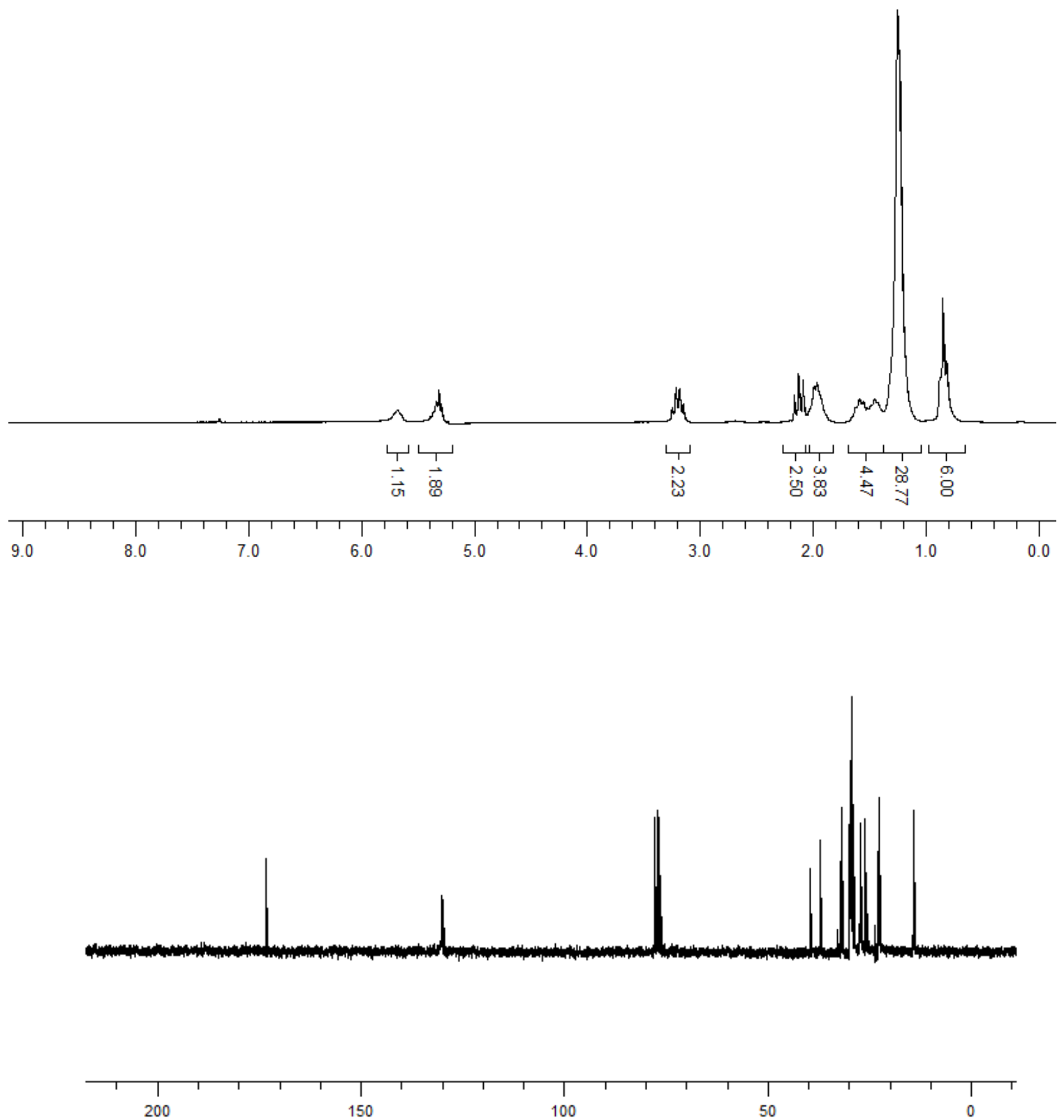

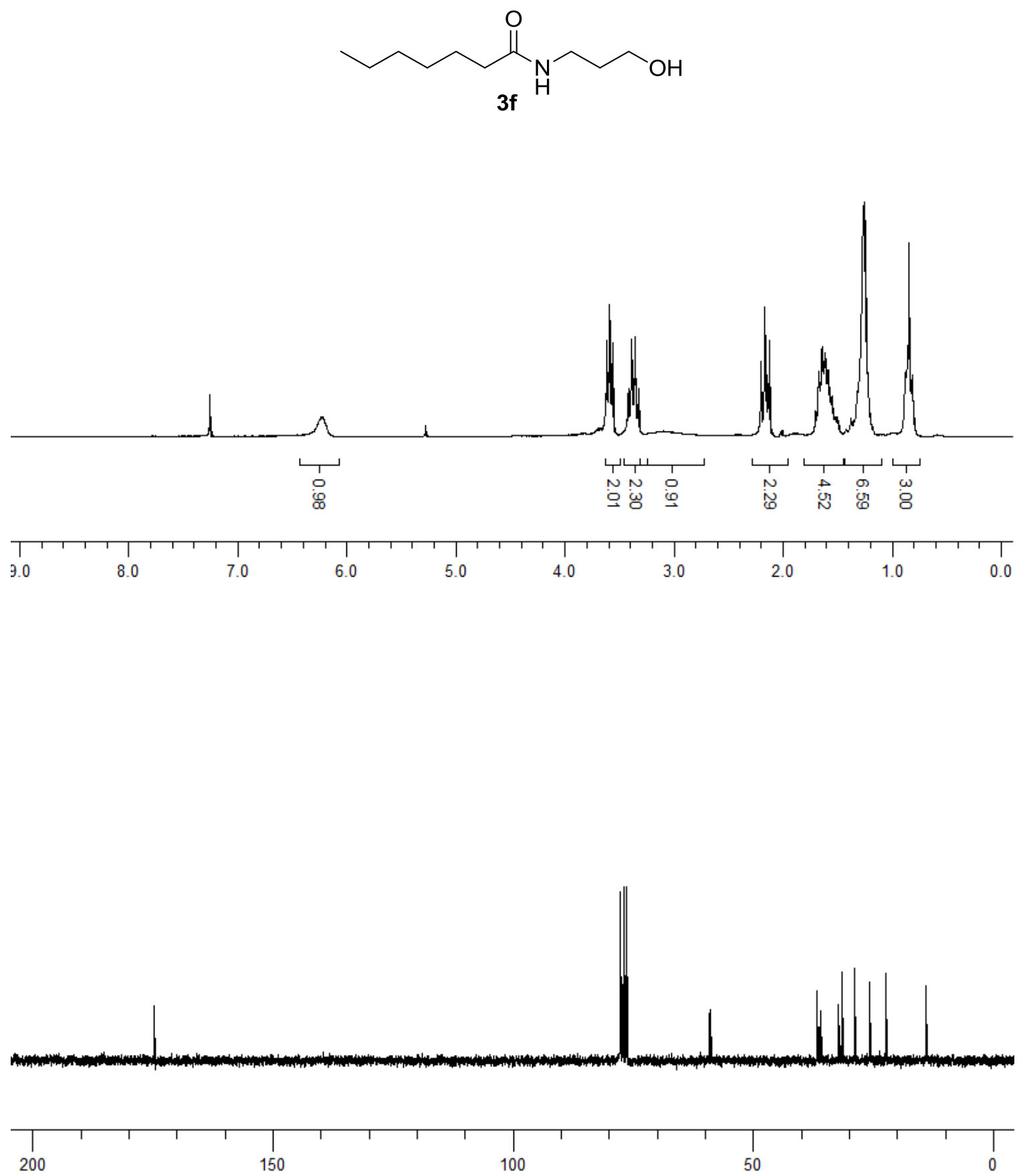

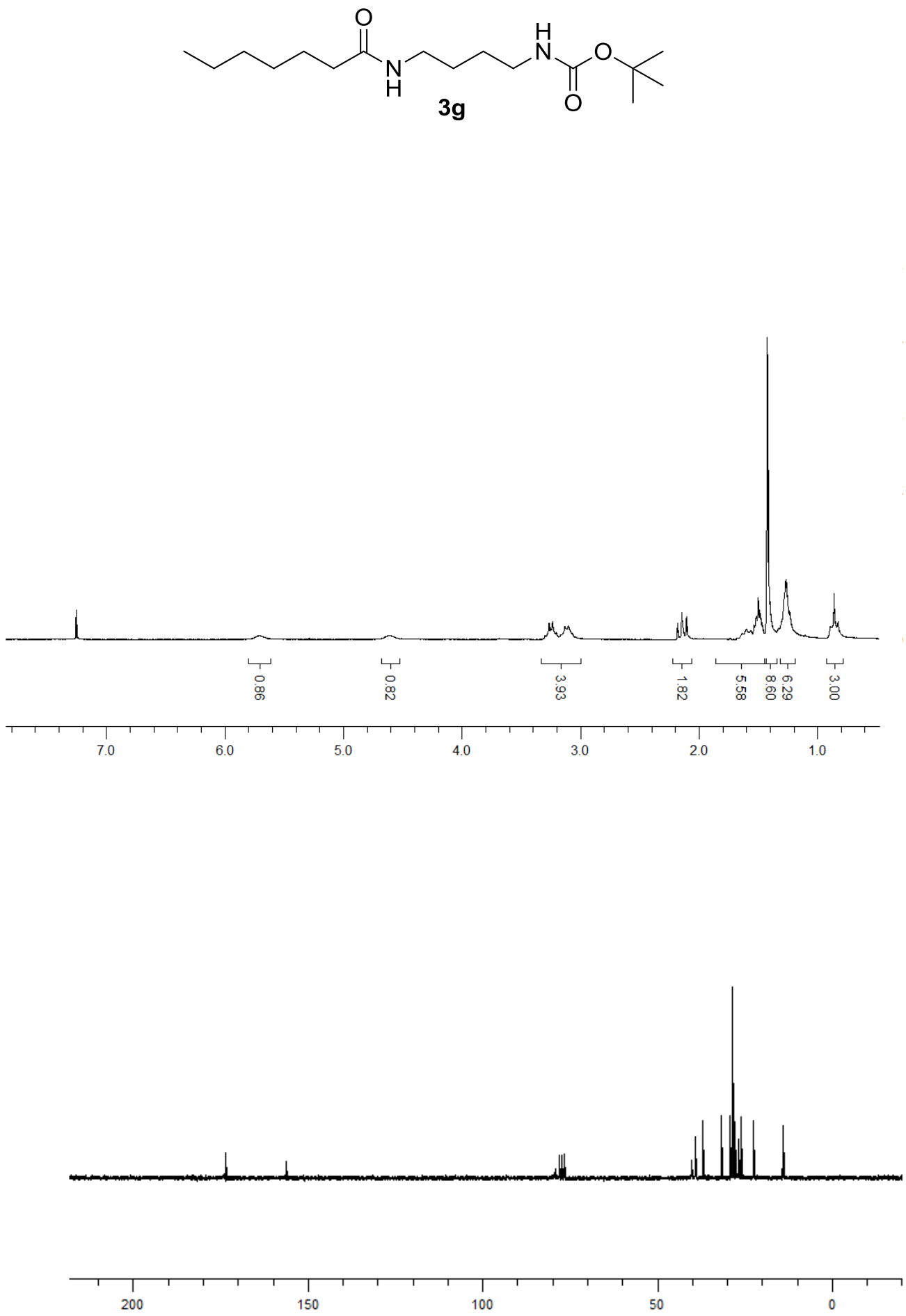
<smiles>CCCCCCC(=O)NCCCC(=O)OCC</smiles>
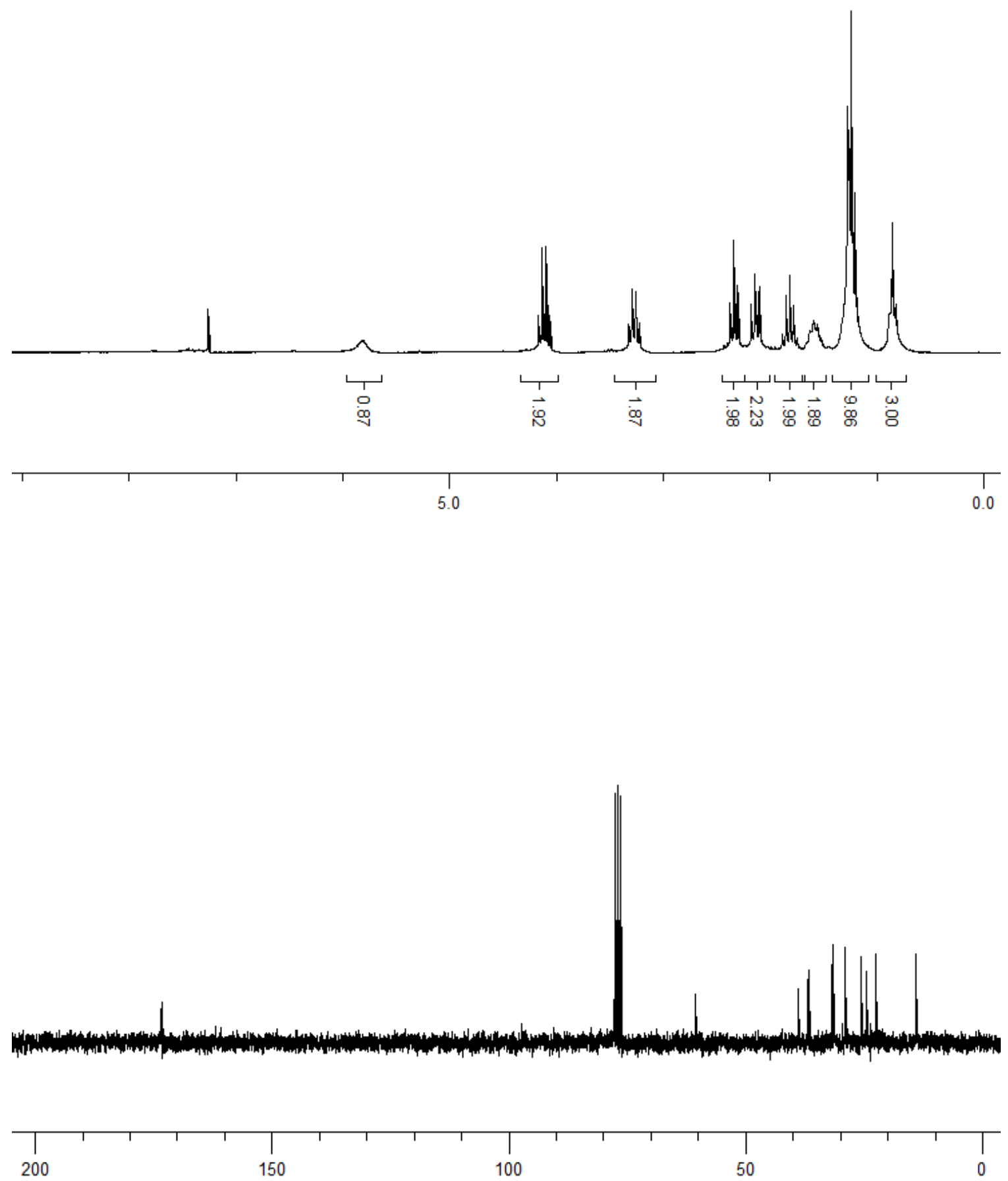

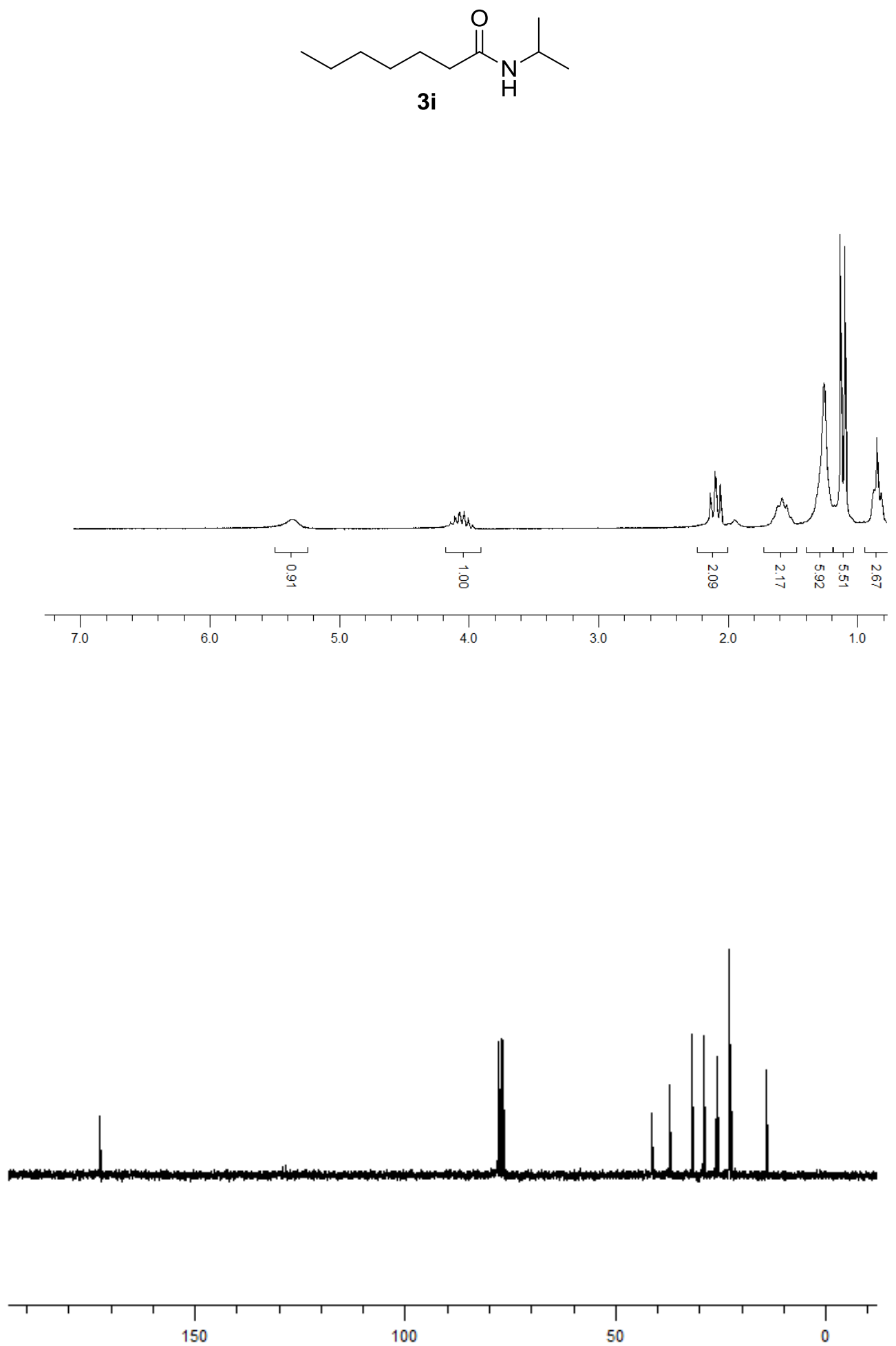


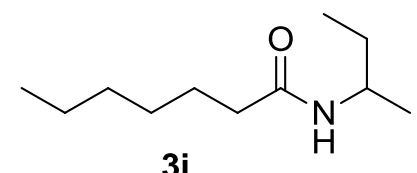

3j
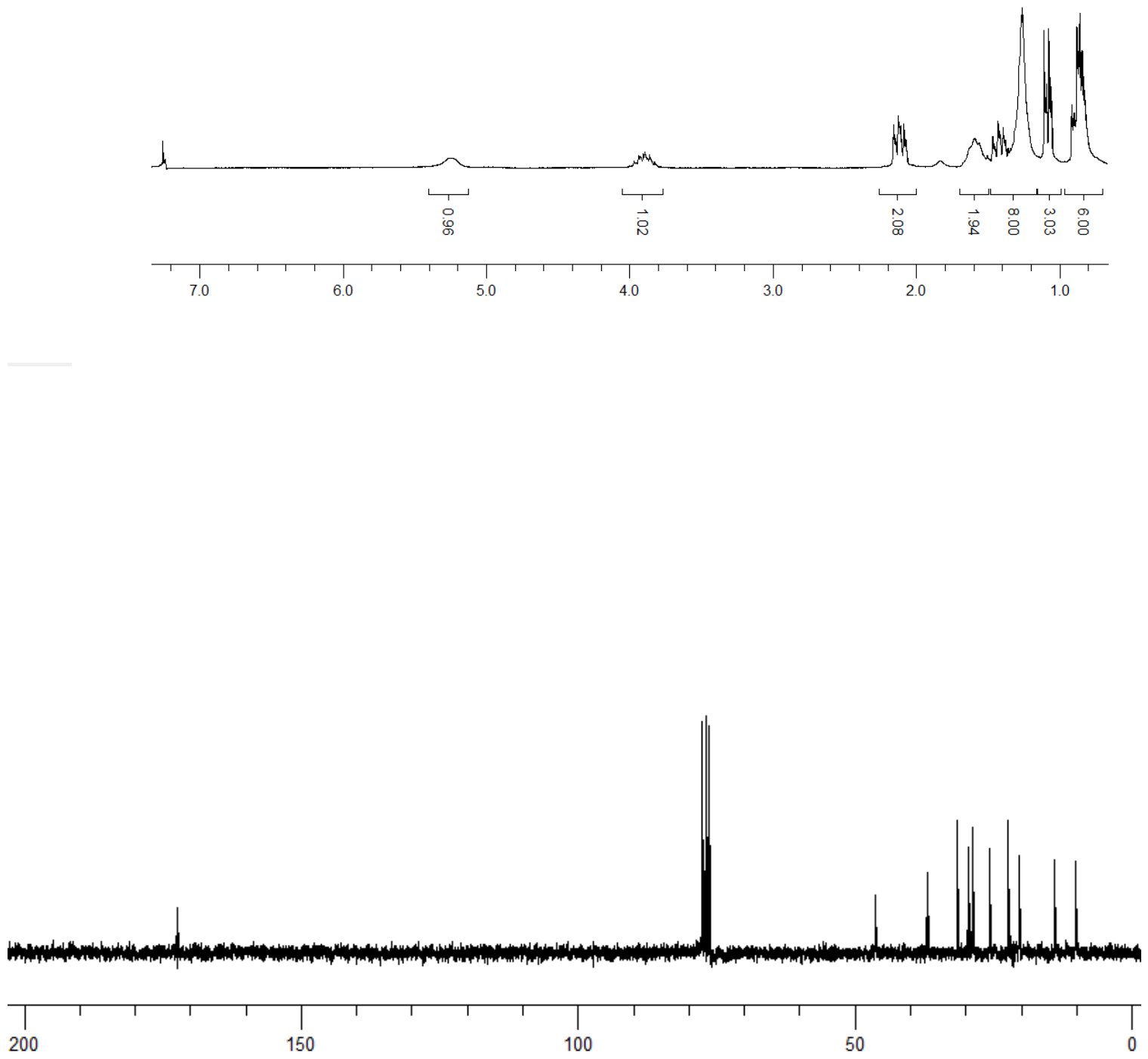

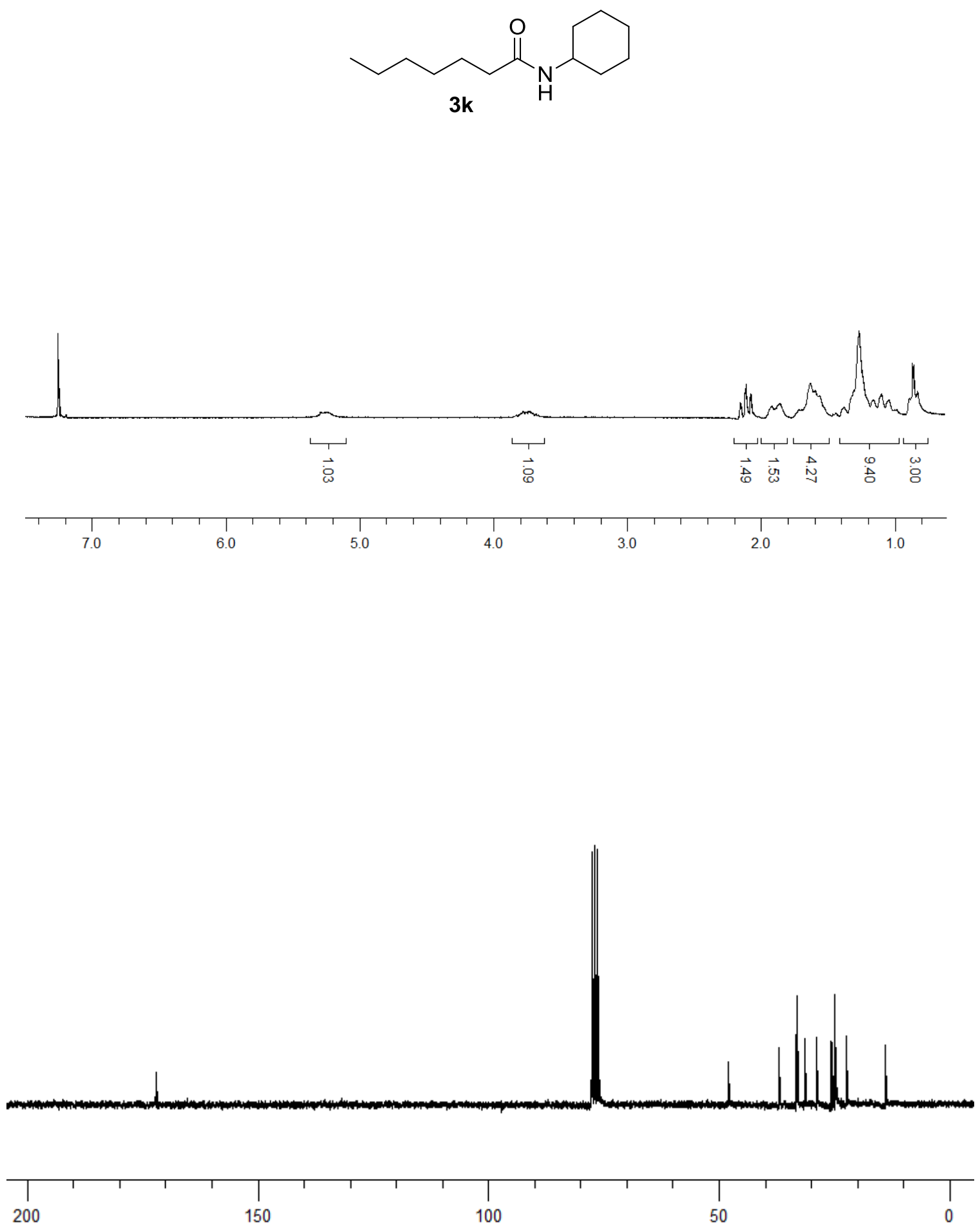


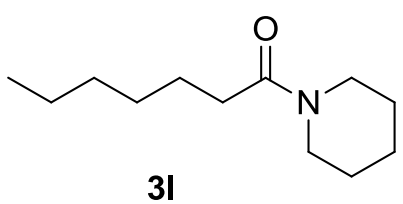

3I
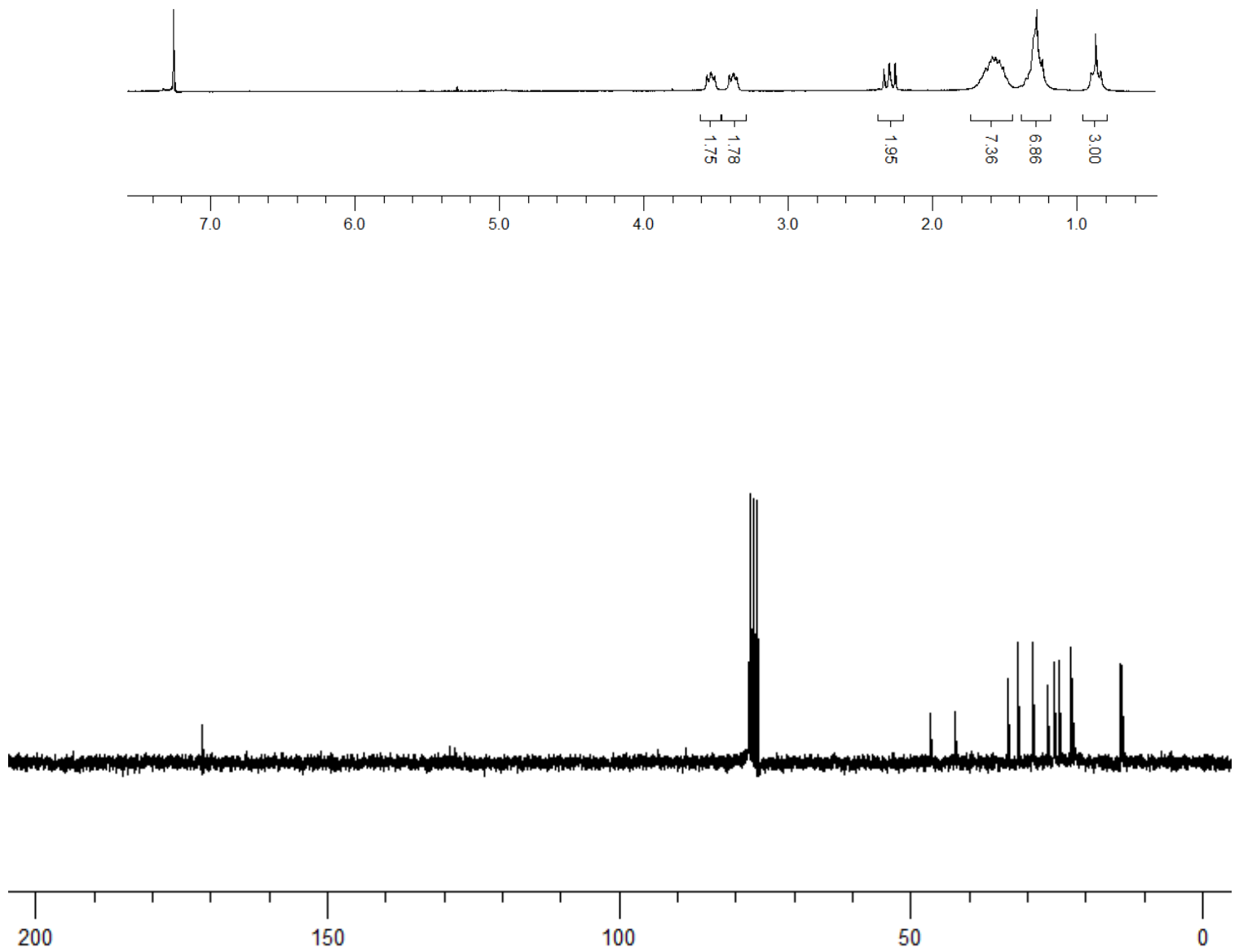


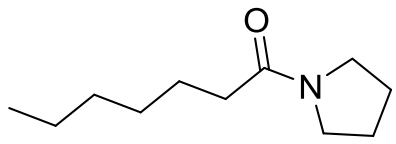

$3 \mathbf{m}$
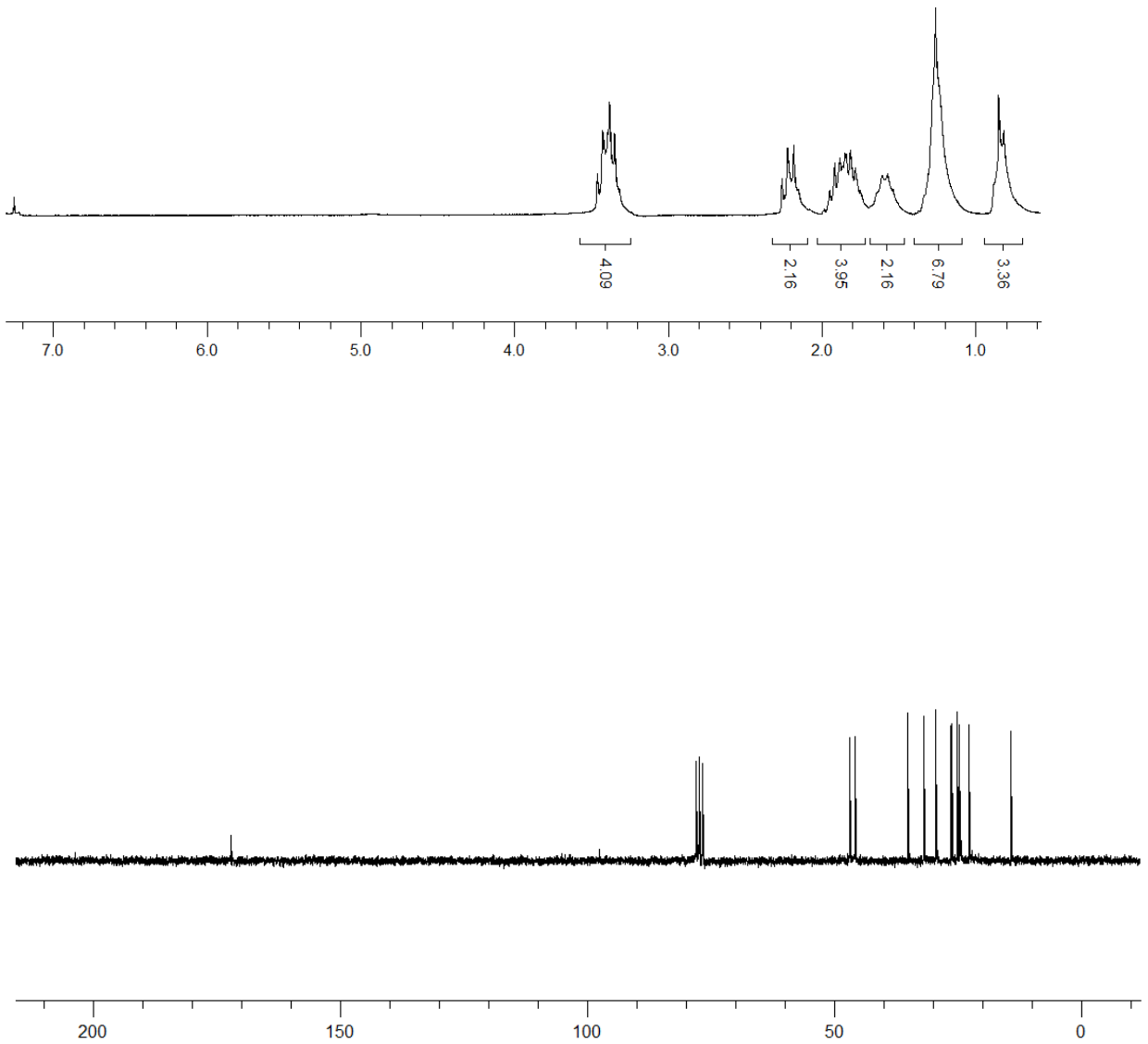


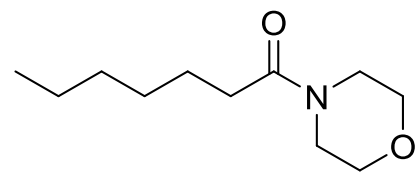

$3 n$
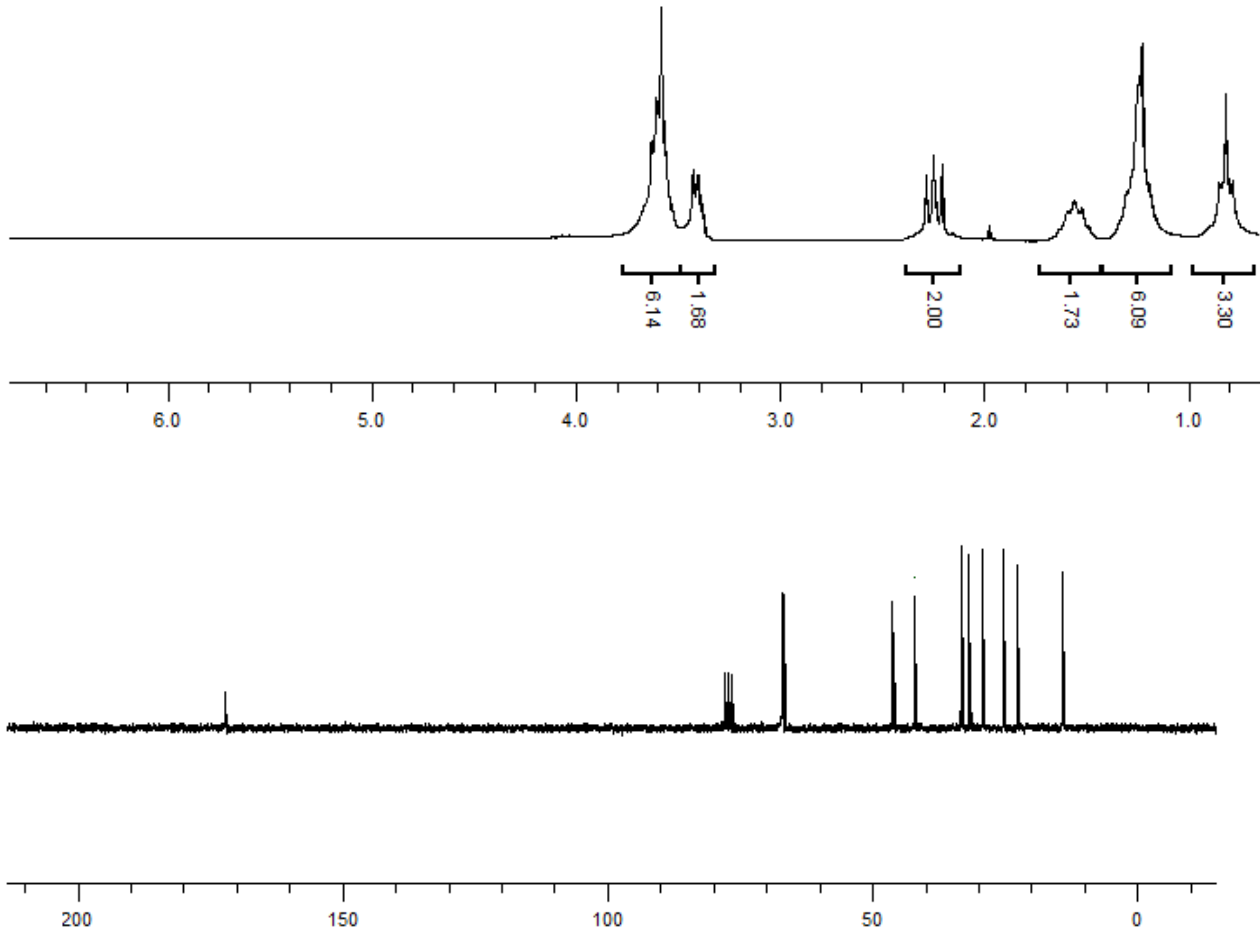


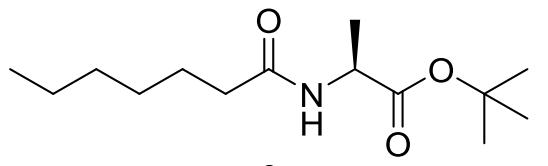

30
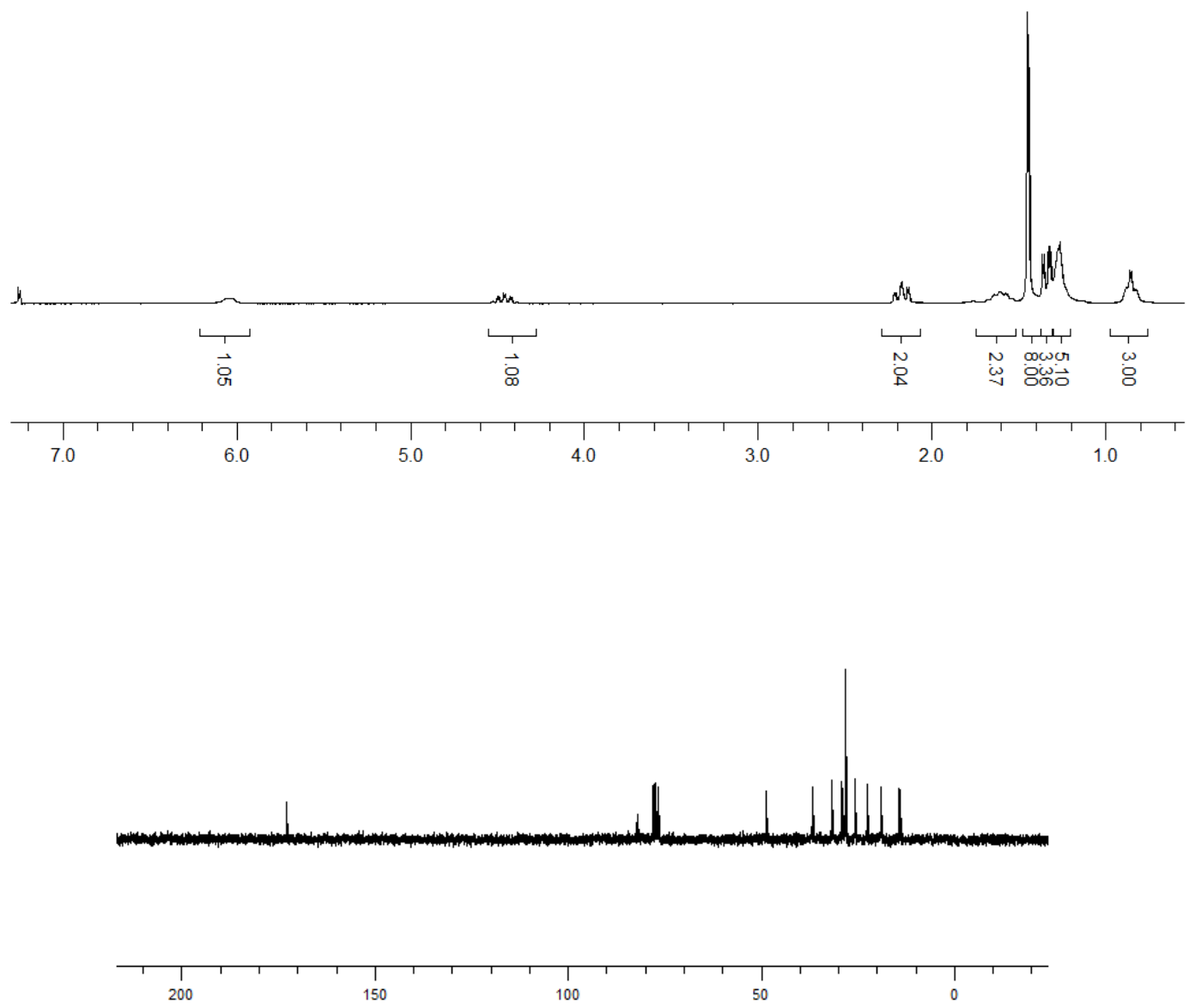
<smiles>CCCCCCC(=O)N[C@@H](Cc1ccccc1)C(=O)OC</smiles>
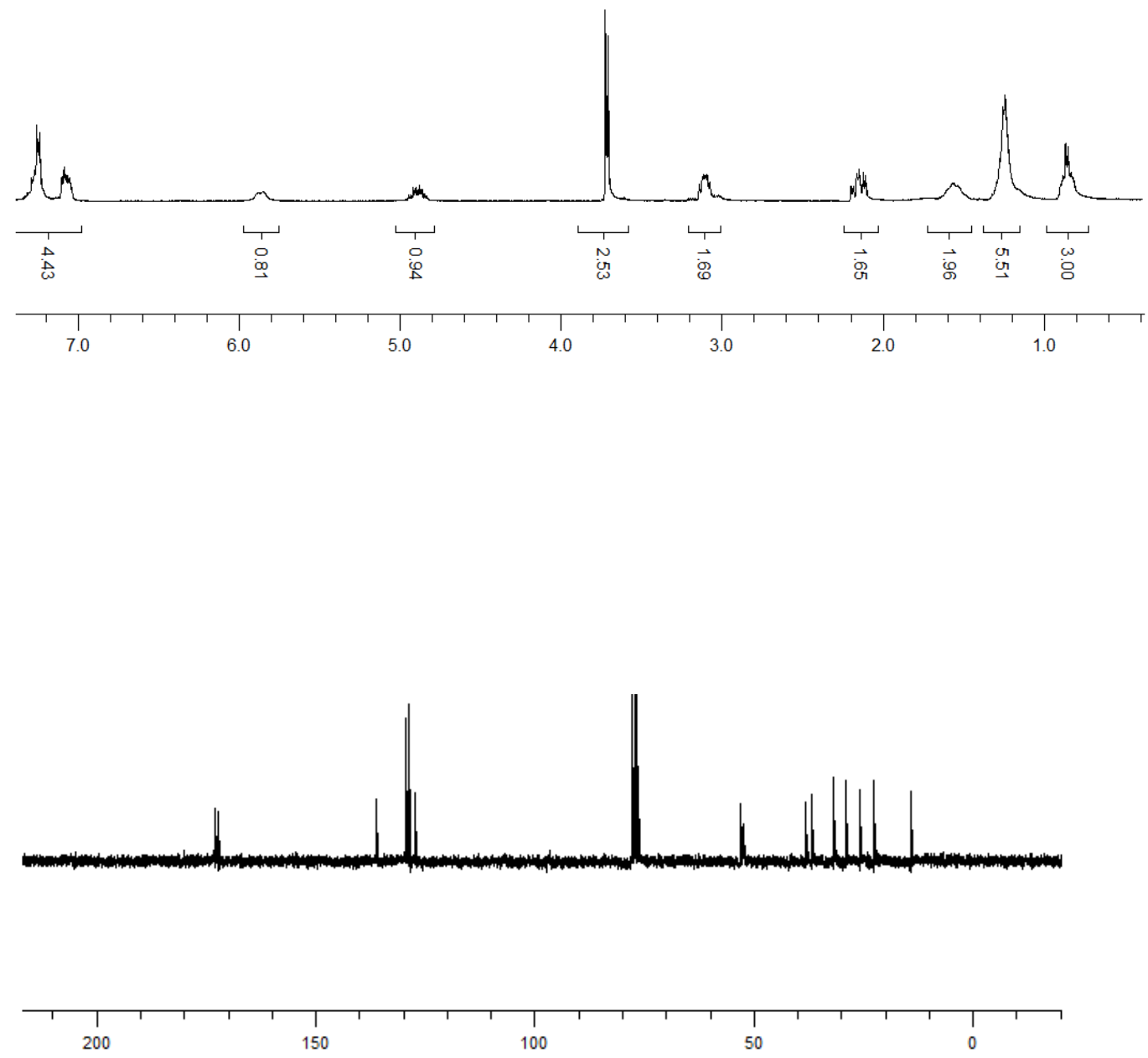
<smiles>C=CCNC(=O)CCC</smiles>
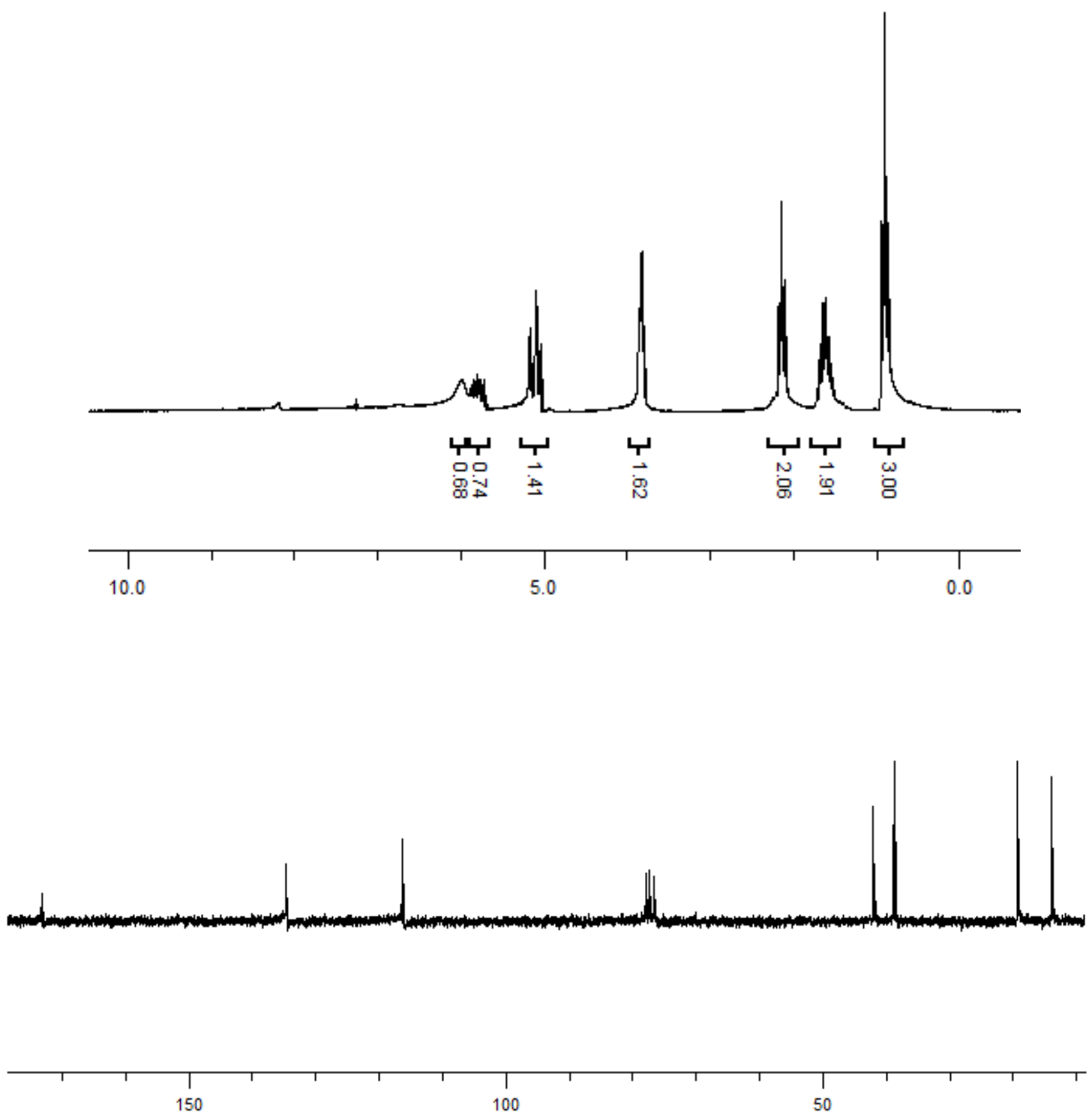

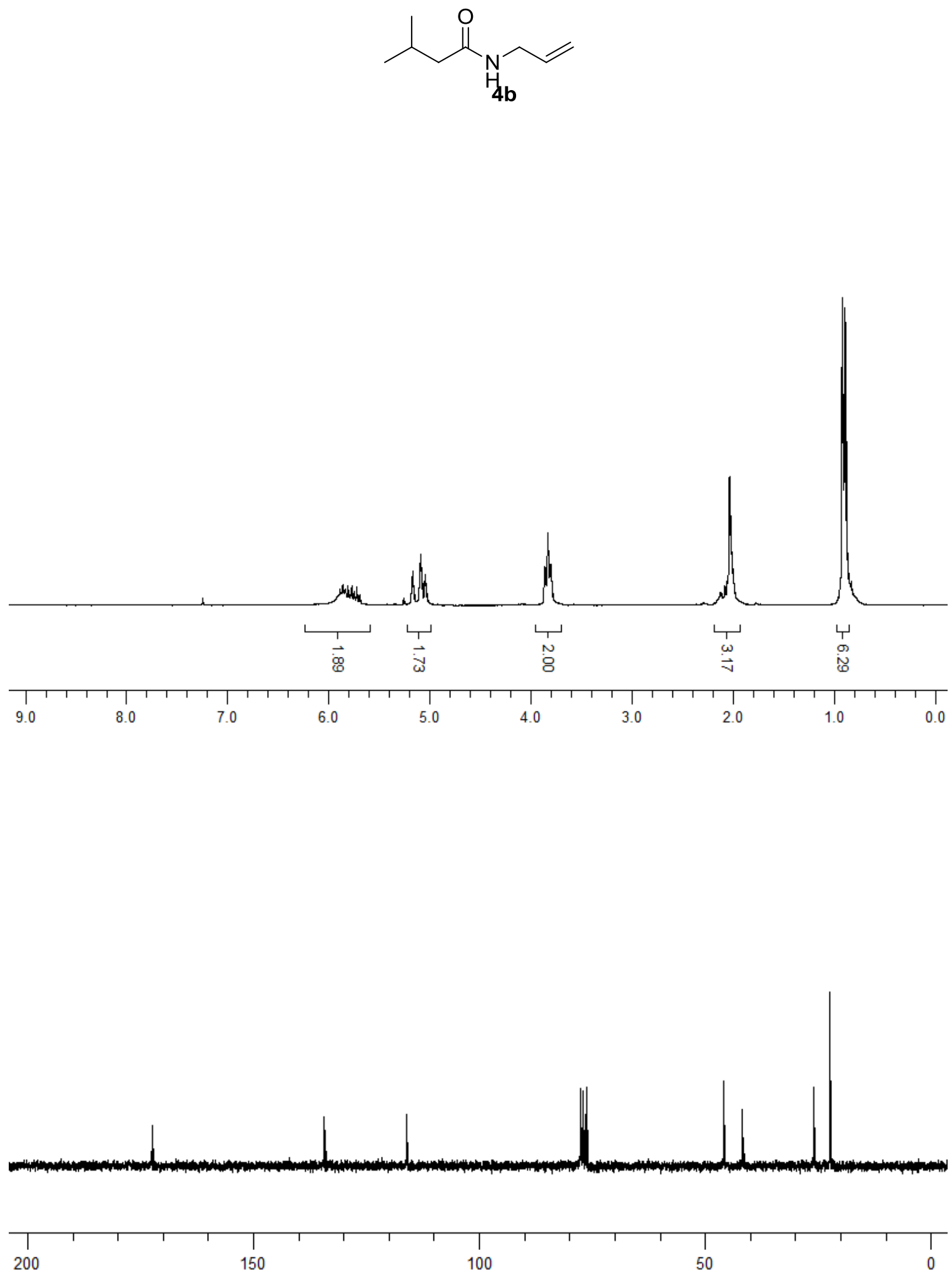
<smiles>C=CCNC(=O)CCc1ccccc1</smiles>
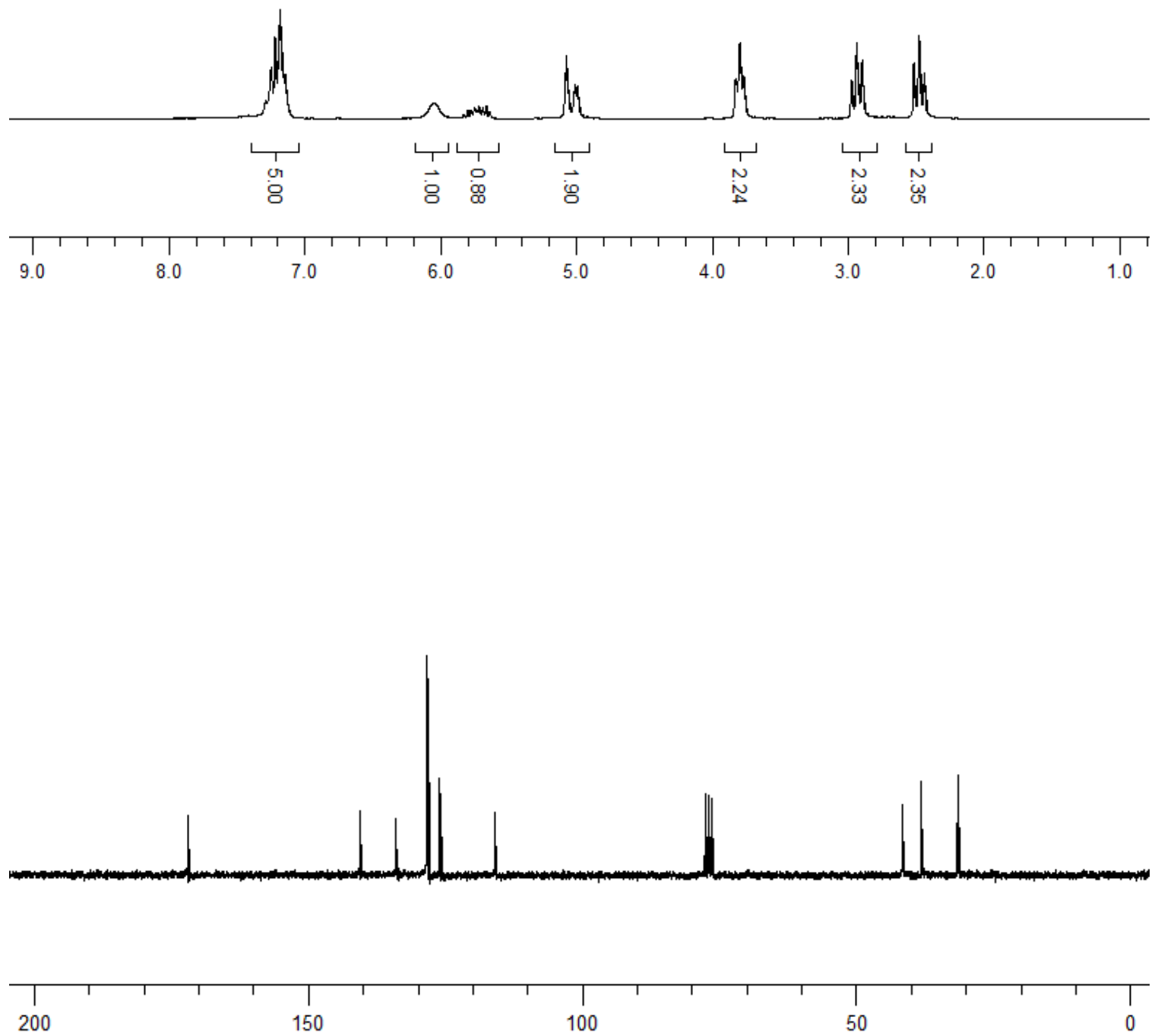

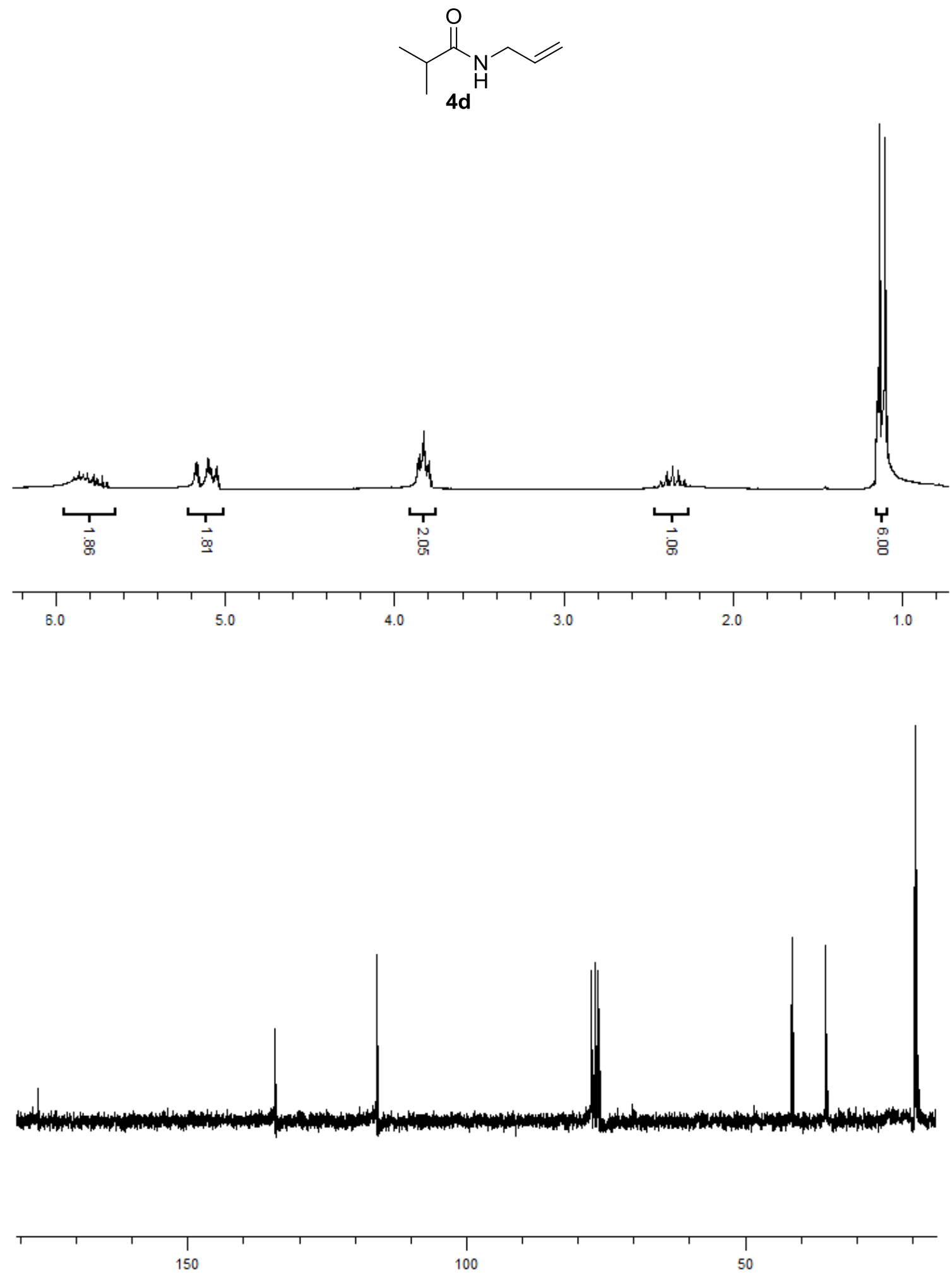
<smiles>C=CCNC(=O)C1CCCCC1</smiles>
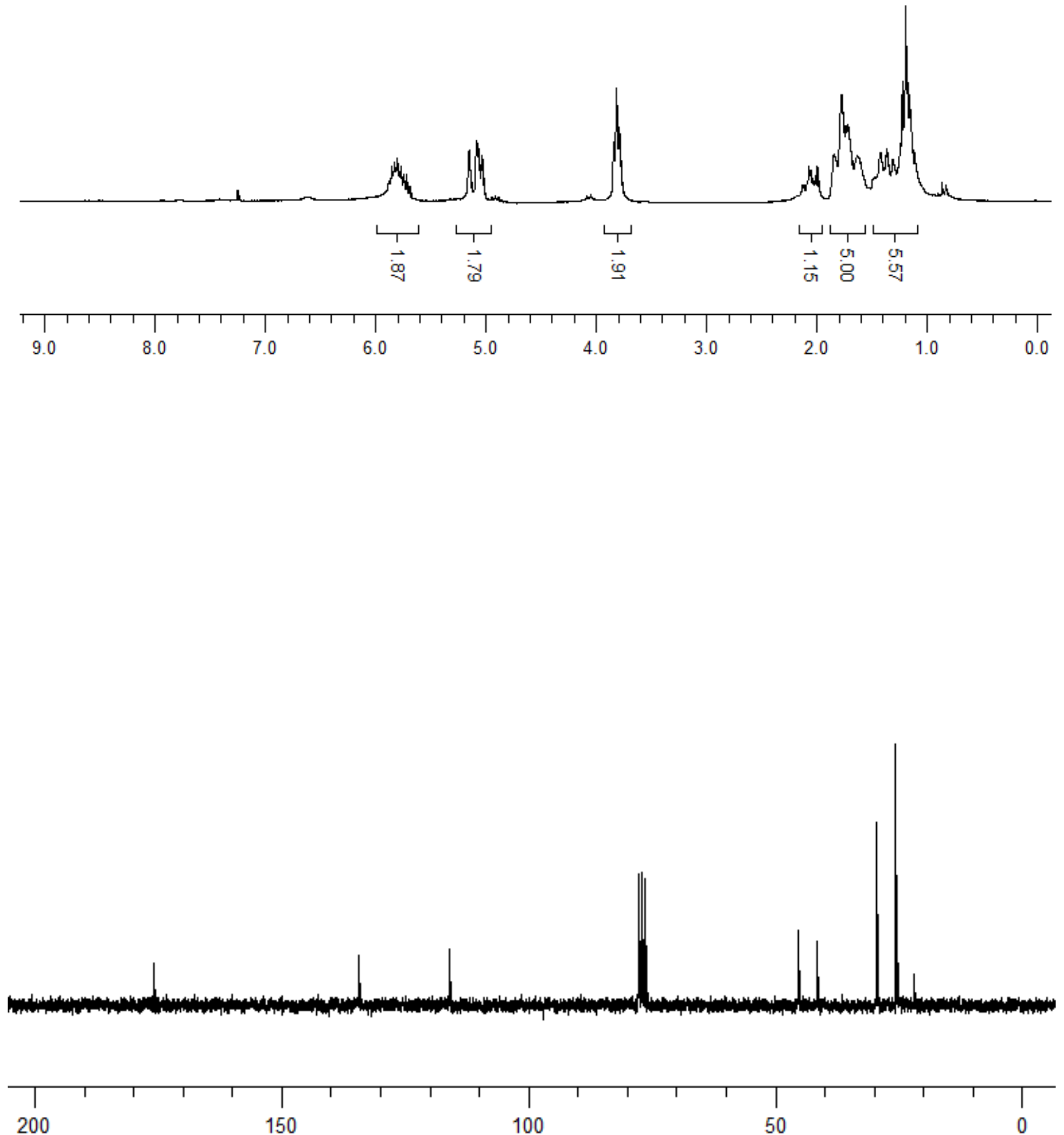
<smiles>[CH]CCNC(=O)C(C)CC</smiles>
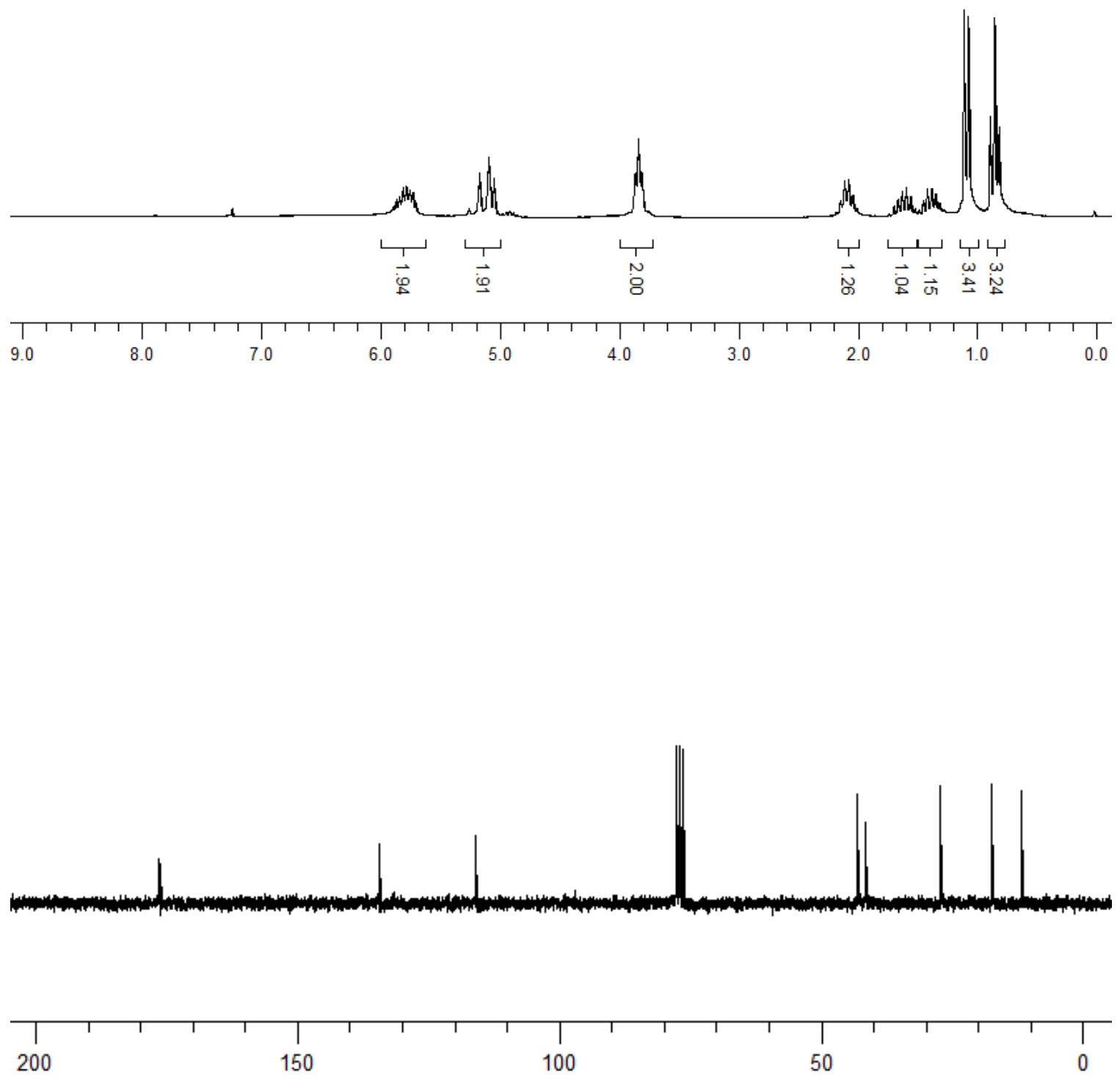

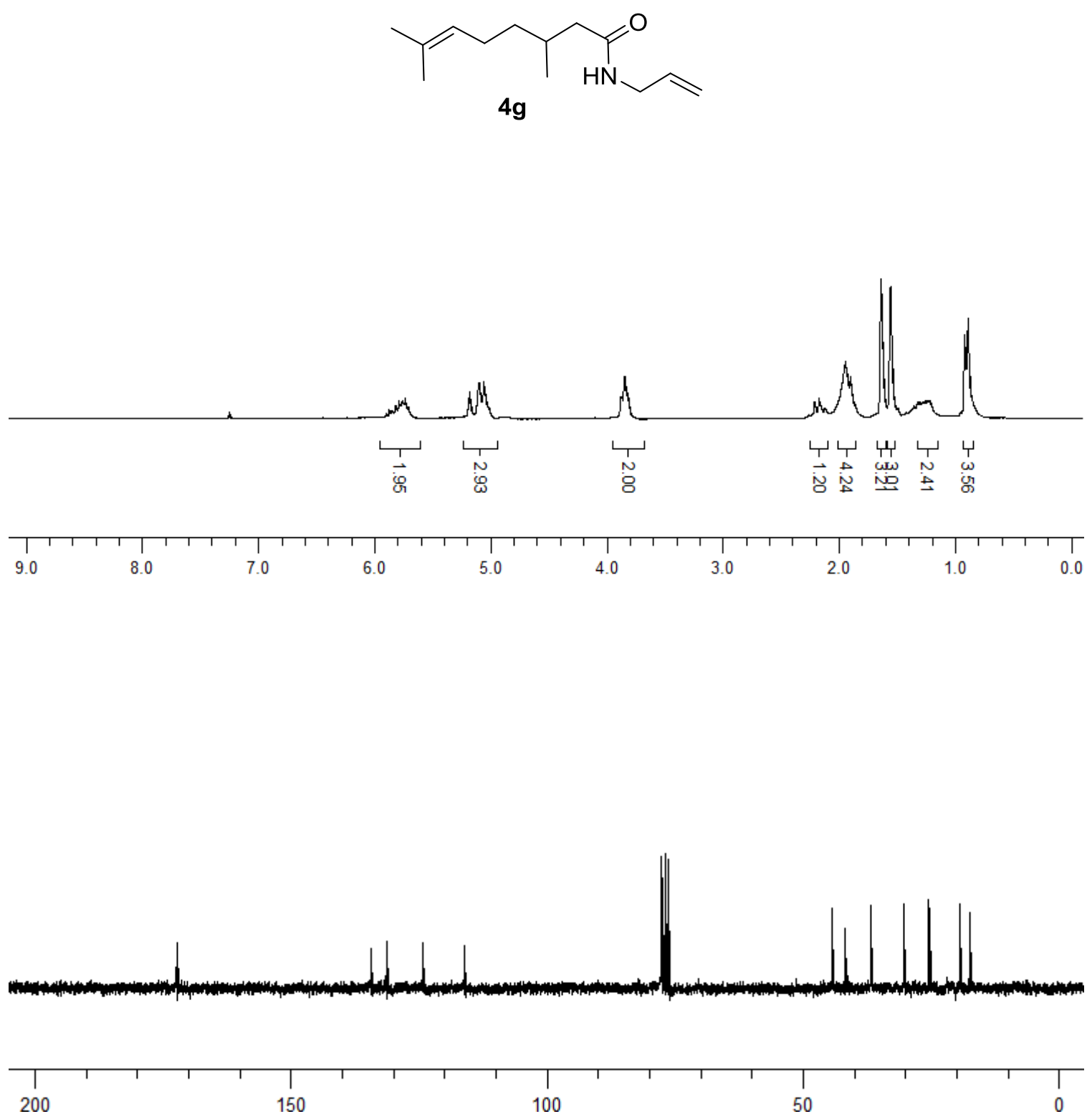
<smiles>C=CCNC(=O)c1ccccc1</smiles>
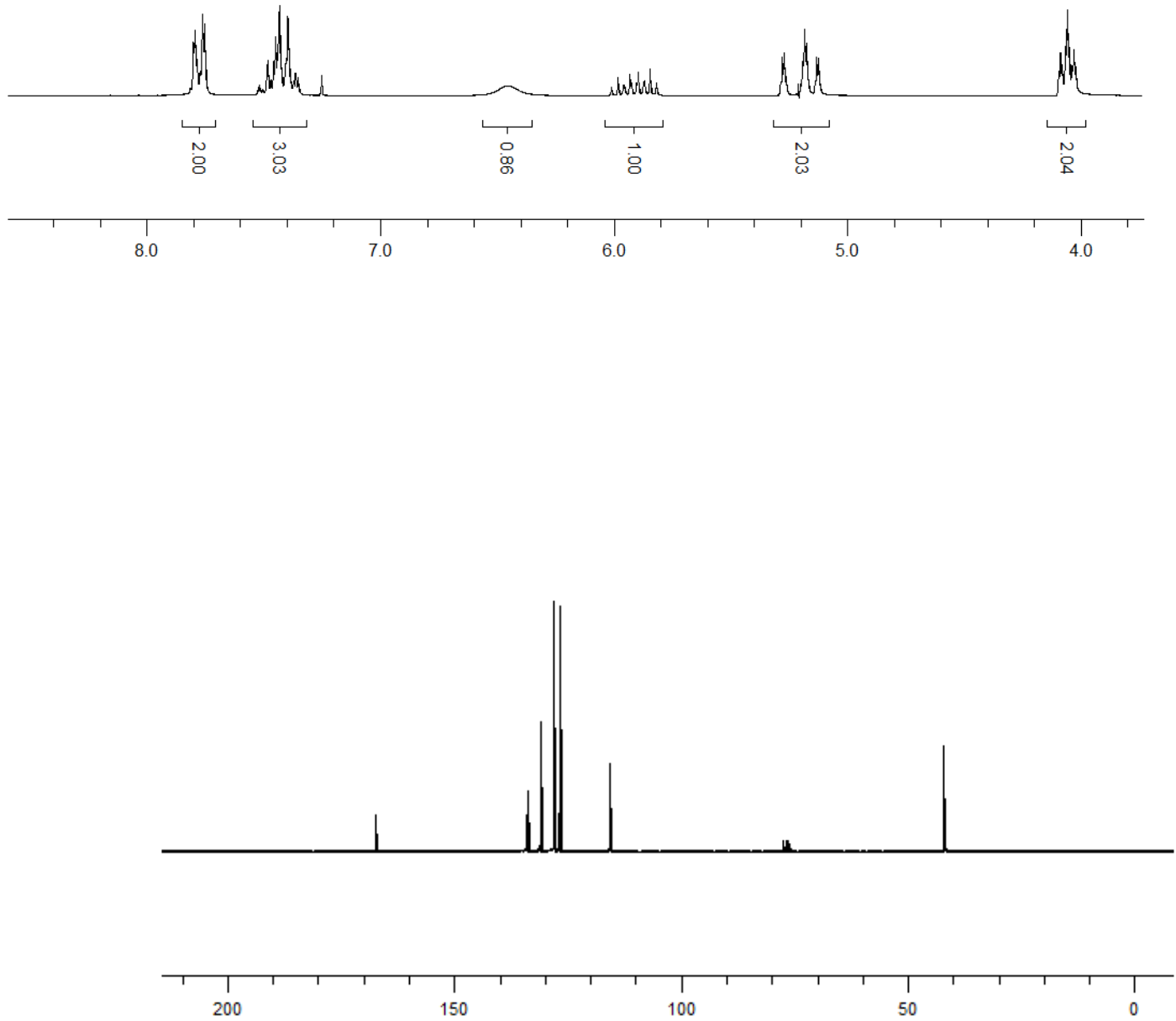
<smiles>C=CCNC(=O)c1ccc2ccccc2c1</smiles>

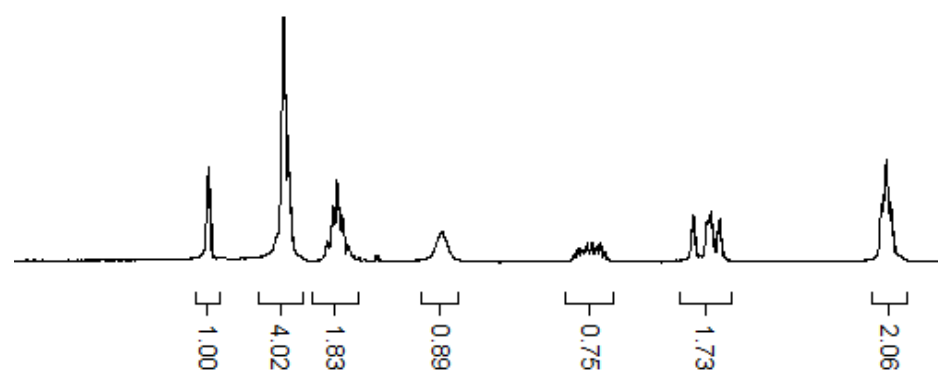

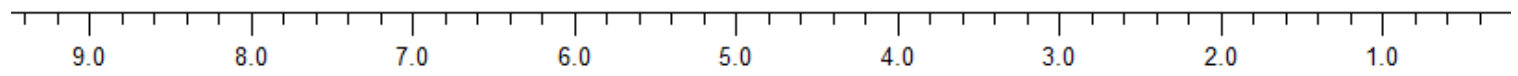
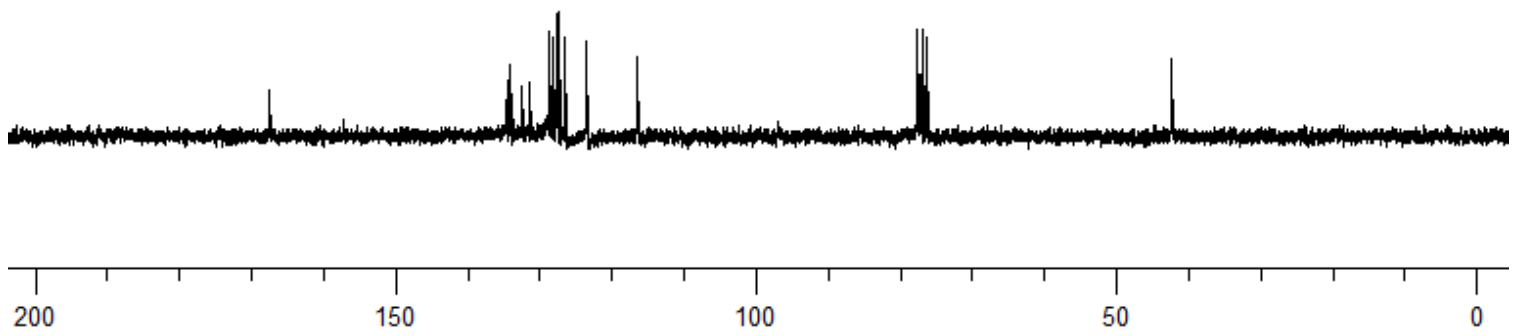
<smiles>C=CCNC(=O)c1ccc(Br)cc1</smiles>
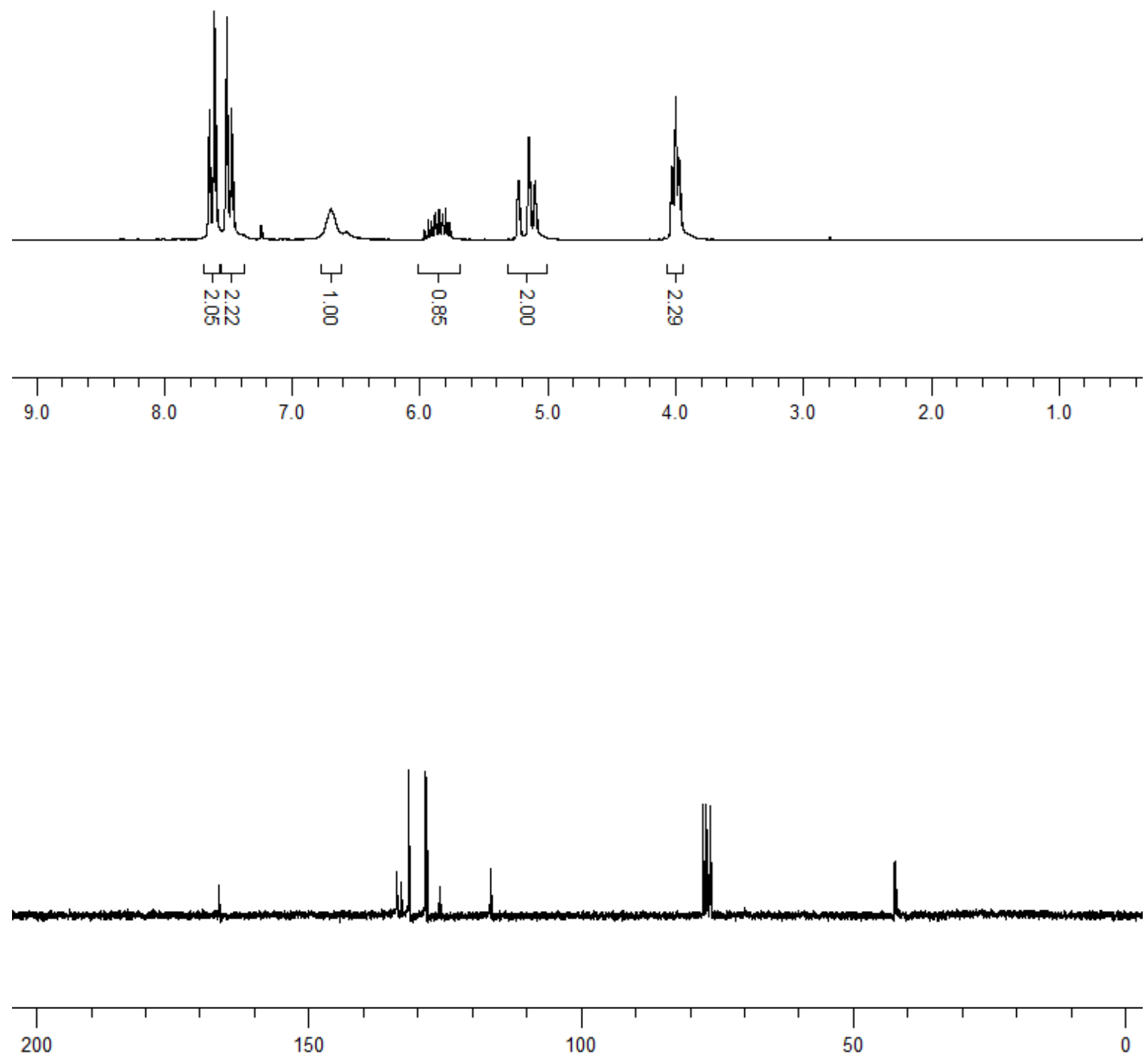
<smiles>O=C(NCCO)c1ccc(Cl)cc1</smiles>
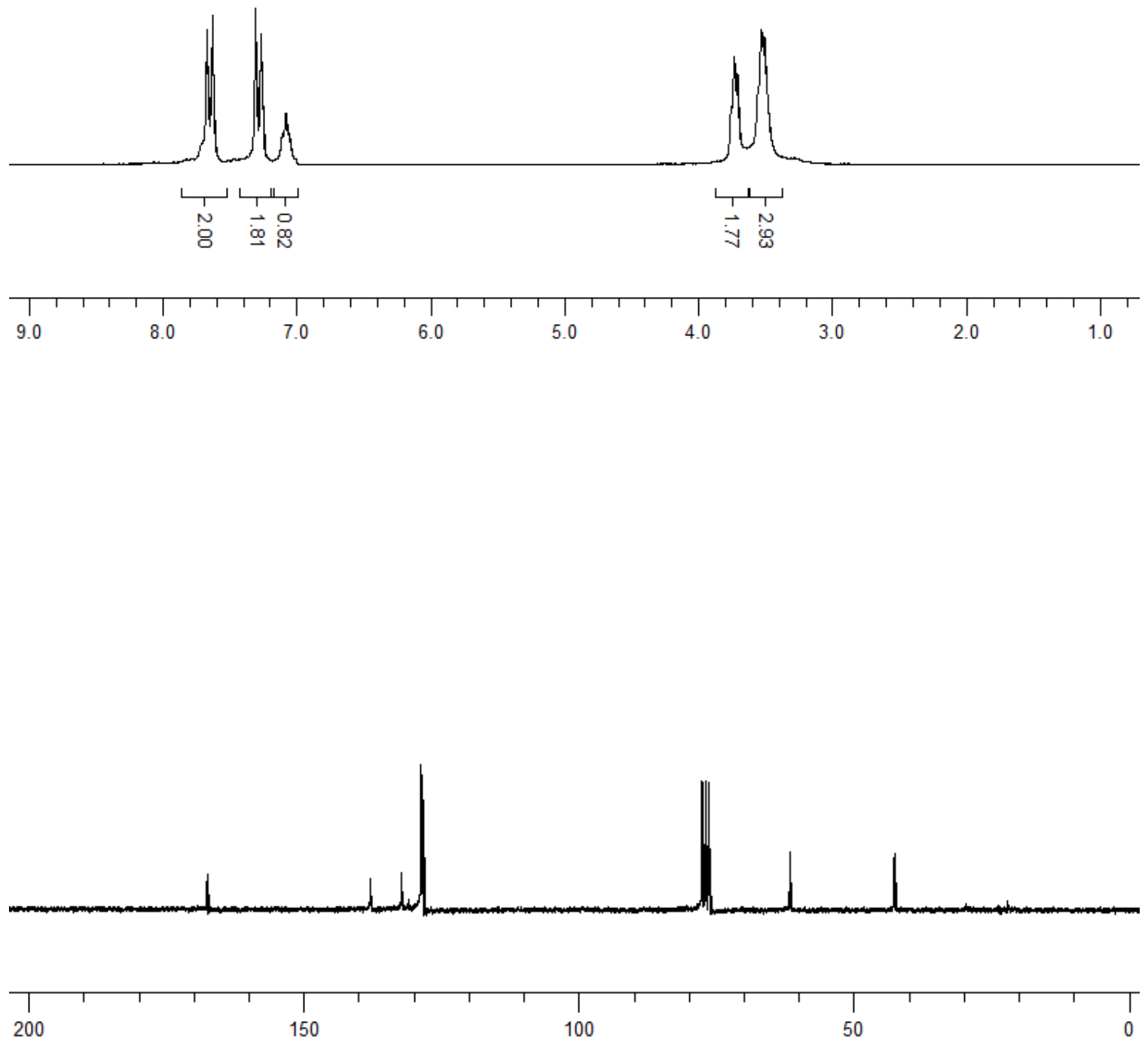
<smiles>O=C(NCCN1CCOCC1)c1ccc(Cl)cc1</smiles>
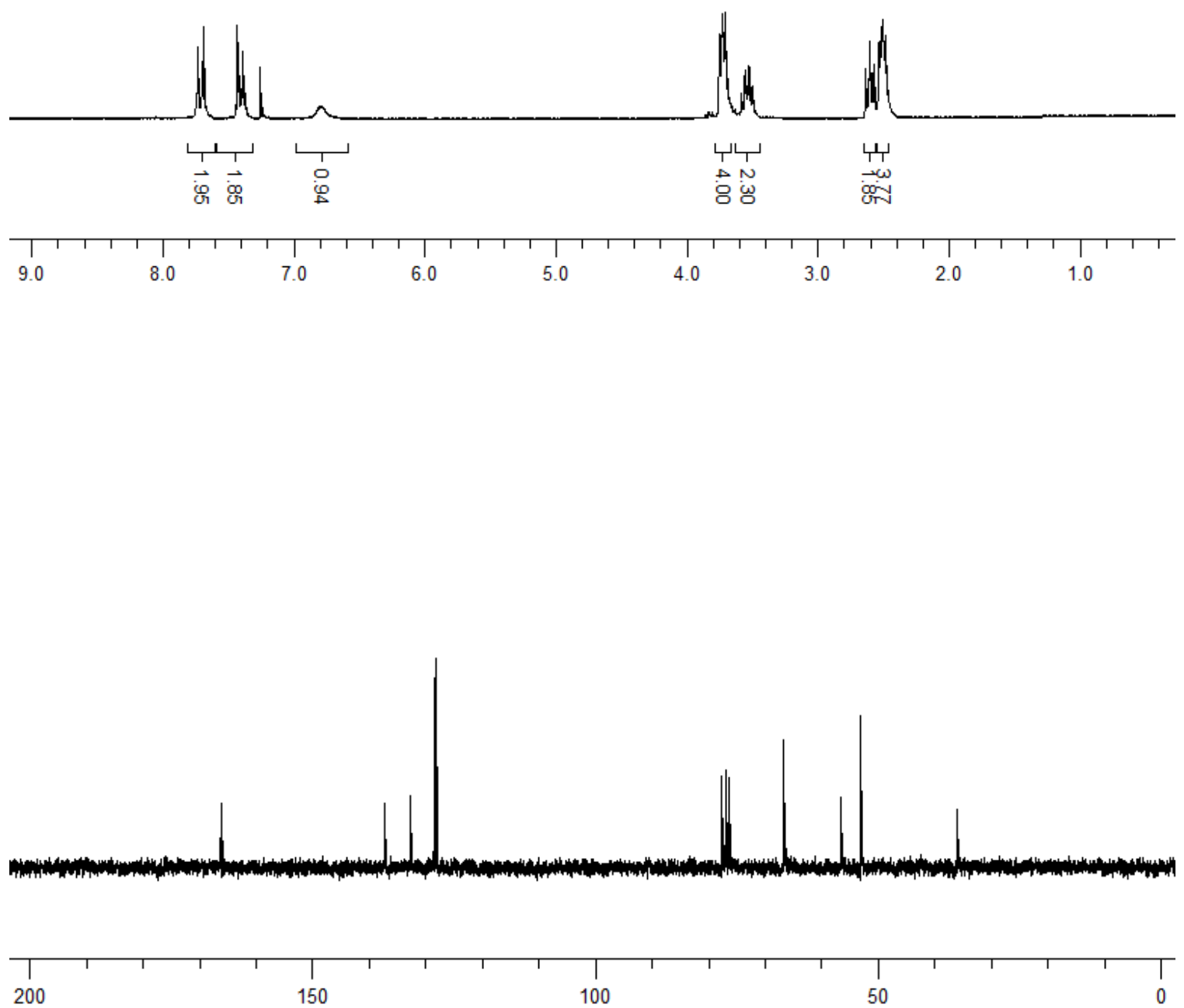


\section{HPLC DATA}

Following the same synthetic procedure, heptanal was reacted with racemic H-Phe-OMe to afford racemic amide 3n. Utilizing chiral HPLC (Chiralapak AD-H, hexane: $\mathrm{PrOH}$ 92:8, $1 \mathrm{~mL} / \mathrm{min}$ flow rate, we separated the two enantiomers $[(R)$-methyl 2-heptanamido-3-phenylpropanoate retention time: $11.38 \mathrm{~min},(S)$-methyl 2-heptanamido-3-phenylpropanoate retention time: $16.94 \mathrm{~min}$ ]. After running the synthesized (S)-methyl 2heptanamido-3-phenylpropanoate 3n under the identical conditions, we confirmed that negligible rate of epimerization had occurred (99\% ee).
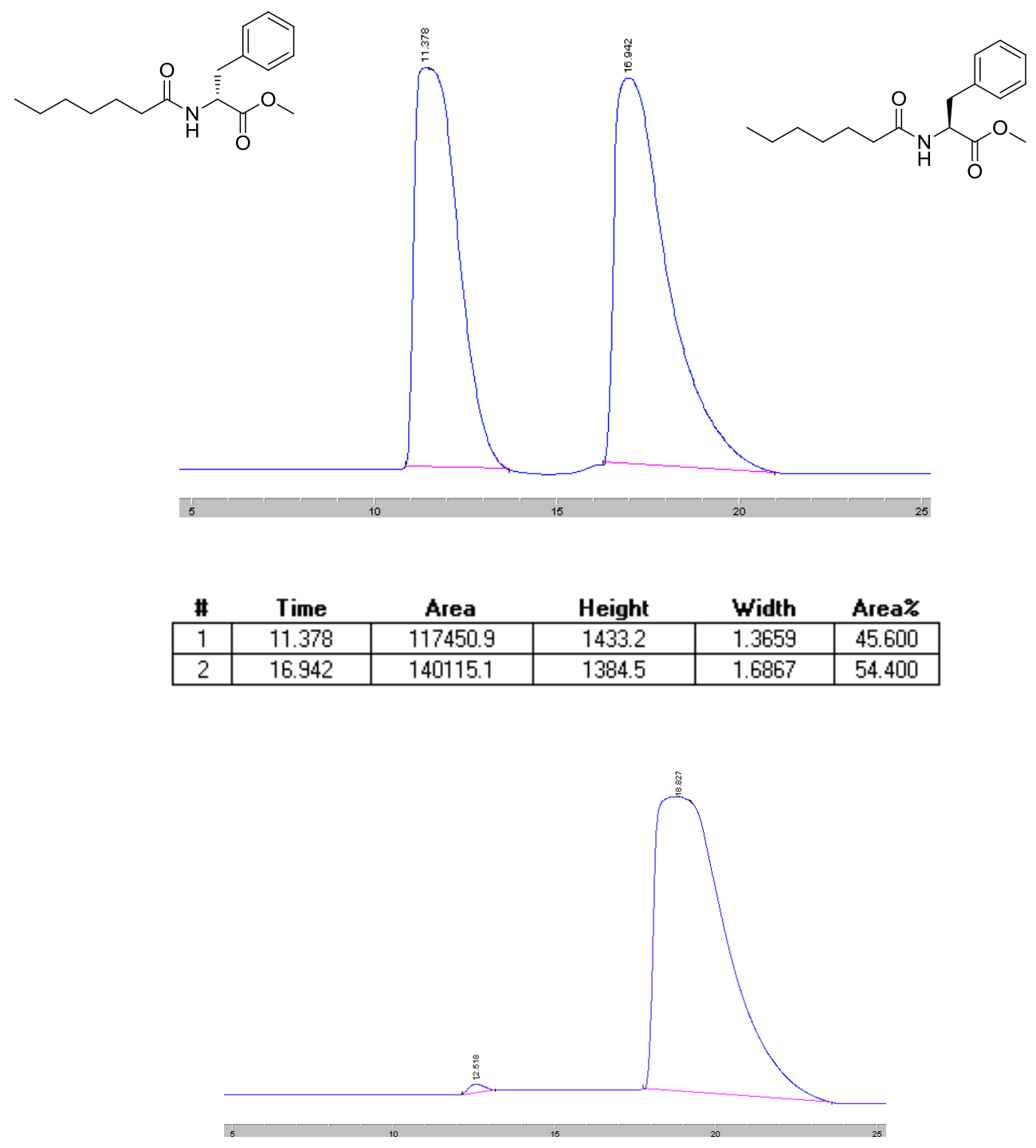

\begin{tabular}{|c|c|c|c|c|c|} 
\# & \multicolumn{1}{c}{ Time } & Area & Height & Width & \multicolumn{1}{c}{ Area\% } \\
\hline 1 & 12.518 & 1338.1 & 39.6 & 0.5626 & 0.637 \\
\hline 2 & 18.827 & 208629.6 & 1365.6 & 2.5462 & 99.363 \\
\hline
\end{tabular}

